\title{
Penalty and Financial Assistance in a Supply Chain with Supply Disruption
}

\author{
Yongjian $\mathrm{Li}^{1}$, Xueping Zhen ${ }^{2,1}$, Xiangtong $\mathrm{Qi}^{3}$, Gangshu (George) $\mathrm{Cai}^{4,5}$ \\ 1, Business School, Nankai University, Tianjin 300071, China
}

2, School of Economics and Management, Shanghai Maritime University, Shanghai 201306,

China

3, Department of Industrial Engineering and Engineering Management, Hong Kong University of Science and Technology, Clear Water Bay, Kowloon, Hong Kong

4, OMIS Department, Leavey School of Business, Santa Clara University, Santa Clara, CA 95053, USA

5, School of International Business, Dongbei University of Finance and Economics, Dalian 116025, China

\begin{abstract}
In a supply chain, when the supply is hit by an unexpected disruption, the supplier may face certain financial difficulty to resume normal production, causing a supply shortage as well as a loss to the manufacturer and the entire supply chain. Combining a penalty term in writing contracts with the provision of financial assistance is the "carrot and stick" approach used by a manufacturer to deal with supply disruption. This article investigates how the manufacturer, in a better financial situation, may use ex-ante penalty terms and ex-post financial assistance to compel the supplier to recover its production capability as much as possible. We find that, the MS (integration of financial assistance and the non-delivery penalty) is the best strategy for the manufacturer in most situations, but it is not a win-win strategy. An interesting result contrary to the conventional wisdom, is that the optimal delivery quantity for the supply chain under the centralized decision-making is less than that under the decentralized decision-making.
\end{abstract}

Keywords: Supply disruption; Capital constraint; Penalty for non-delivery; Financial assistance 


\section{Introduction}

A supply chain could suffer from major supply disruptions caused by fire, earthquake, terrorism, labor strikes, manufacturing quality failures, supplier bankruptcies, and so on. A supply disruption not only directly affects the supplier, but also causes significant loss to the downstream of the supply chain. For example, in February 1997, a fire in a Toyota brake-supplier plant led to a two-week shutdown of 18 Toyota plants across Japan, resulting in losses amounting to US\$195 million [1]. In March 2000, lightning caused a fire that shut down the Philips semiconductor plant in Albuquerque, New Mexico, leading to a shortage of components for both Ericsson and Nokia. As indicated in its 2001 annual report, Ericsson announced a major loss of about $\$ 400$ million, which can be directly attributed to the supply interruption [2]. In March 2011, one of the strongest earthquakes hit Japan, triggering a massive 23-foot tsunami and a nuclear crisis, which subsequently led to a global supply disruption. For instance, the big three Japanese automakers, Toyota, Honda, and Nissan, suspended production at their respective domestic facilities due to earthquake damages and disruptions in the flow of auto parts from their suppliers [3]. Nissan, one of the heavily affected companies, had at least nine of its Japanese vehicle and parts factories and 35 suppliers affected by the disaster [4]. Supply disruptions often cause serious damages to the operational performance and lead to losses of shareholders' wealth and reputation [5]. When backup suppliers are not immediately available, the key factor for the supplier in overcoming supply disruption is to quickly restore its normal production capability. However, in many cases, the disrupted supplier may be unable, or at least reluctant, to do so because of many reasons, such as financial constraints.

In practice, a lot of operational tools can be used to manage disruption risk. As Tomlin and Wang [6] state, there are five major disruption risk management strategies: inventory, supply diversification, backup supply, demand management and supply chain strengthening. They also analyze each strategy's pros and cons and suggest that managers should align the strategy with the operational environment. Except supply chain strengthening that seeks to reduce the likelihood of supplier-related disruption, all other four strategies focus on minimizing the negative consequences of supply interruptions.

Besides the above five strategies, demanding a penalty as a type of default clause is another common ex-ante strategy in disruption management. Generally speaking, a default clause clearly states what actions can be taken if a partner fails to fulfill its obligation. In the context of a supply disruption, 
when the supplier breaches the contract by failing to supply goods or perform a service as promised, the manufacturer can claim a compensation or penalty for the damage under a default clause. The penalty strategy is relatively easy to implement, partly because it does not require coordination with the supplier after a disruption. However, a question naturally arises: is a penalty term an effective strategy to protect a manufacturer from the losses brought about by a supply disruption?

Based on the information from interviewing industry managers, we learn that, to maintain supply chain partnership, the purpose of penalizing suppliers under a disruption is to push the supplier to restore normal supply as soon as possible, rather than to exploit the supplier via collecting penalty. Indeed, a high penalty could bankrupt the supplier, which would in turn hurt the manufacturer from the perspective of long-term sustainability. To this end, the manufacturer must also consider other rational options aside from a penalty clause.

Strengthening supply chain, one of strategies shown by Tomlin and Wang [6], can include the ex-ante and ex-post approaches. While the ex-ante approach means that supply chain enterprises can cooperate with each other to reduce the frequency and/or severity of supply problems, the ex-post treatment suggests that the cooperation between supply chain partners occurs after a disruption in order to reduce loss by helping the disrupted company recover production. In recent years, the importance of mutual assistance between supply chain enterprises as an attractive ex-post treatment strategy has been recognized. In the case of a supply disruption, reasonable assistance can enhance the sustainability of supply chain with lower costs. One main approach is through financial assistance, which includes loans, donations, and trade credits. Some cases of financial assistance extended to disrupted suppliers are listed below.

- When the Indonesia Rupiah was devalued by more than $50 \%$ in 1997 , many Indonesian suppliers were unable to pay for the imported components or materials, and hence, were unable to fulfill orders for their customers. Li and Fung (www.lifung.com), the largest trading company in Hong Kong for fashionable goods provided financial assistance such as credit lines, loans, and so on, to these affected suppliers, thus ensuring continued production and delivery [7].

- In 2009, auto-parts maker American Axle \& Manufacturing (AAM), the main supplier of General Motors, was severely affected by the decline of the U.S. auto industry and the subsequent reduction in vehicle sales. General Motors expedited a US\$100 million loan to 
AAM to help the latter avoid bankruptcy [8].

- In 2012, Autodom Ltd., a supplier of parts to local units of Ford, Toyota and General Motors, shut down its plants in two Australian cities because of the falling demand for locally-built vehicles and increasing operation cost. Ford and General Motors agreed to underwrite US\$6.5 million debt for Autodom to evade shutdown [9].

The objective of this research is to investigate the above mentioned complementary strategies to ensure continued production in a supply chain suffering from a supply disruption. The first strategy is the ex-ante penalty strategy (PS) in which the manufacturer determines a penalty term for any future supply shortage to reduce the shortage loss and compels the supplier to recover production as soon as possible. The second strategy is the ex post financial assistance strategy (FAS), in which the manufacturer may loan money to the supplier who suffers a capital constraint after the disruption. It is also possible to employ a mixed strategy (MS) which integrates both PS and FAS.

To compare the above three strategies, we model a single-period supply chain consisting of a supplier and a manufacturer with demand uncertainty. As part of the procurement contract, the manufacturer can set up a penalty term, preventing the profit loss caused by the supplier's delivery shortage, wherein the penalty level is acceptable to the supplier so as not to drive the supplier into bankruptcy. Once a supply disruption occurs, the supplier exerts efforts to recover his production, measured by the delivery quantity. If the supplier suffers from capital constraint in the process of production recovery because of higher production cost, the manufacturer can offer financial assistance to the supplier by loaning money to the supplier. In the Stackelberg game (see Tang et al., [10]), the manufacturer as the leader decides the interest rate, and then the supplier determines the capital to borrow and the delivery quantity as a response. We study the delivery quantity of the supplier, the penalty and financial decisions of the manufacturer and the strategy preference problem.

We find that, in most situations, the MS is the best and robust strategy for the manufacturer. However, the MS strategy is not necessarily mutual beneficial, because the penalty term can hurt the supplier, who instead prefers the FAS. We also show that contrary to the case without a disruption, the delivery quantity under the centralized decision-making can be less than that under the decentralized decision-making when a disruption occurs. We further demonstrate that, when the supplier is capital-constrained, both the supplier and the manufacturer benefit from the financial assistance. Hence, offering financial assistance leads to a win-win outcome for both supply chain partners. 
The rest of the paper is organized as follows. In Section 2, we provide a brief literature review. The model is described in Section 3. In Section 4, we present a benchmark case where the supplier and the manufacturer use a quantity discount contract to coordinate the supply chain. Sections 5 and 6 investigate the PS, MS and FAS, respectively. Sections 7 and 8 analyze the strategy preference of the manufacturer as well as parameter sensitivity, respectively. Section 9 concludes the paper.

\section{Literature Review}

Supply chain disruption has attracted interest from both researchers and practitioners of operations management. Disruption, usually infrequent and temporary, causes a significant change to the system when it occurs. Hendricks and Singhal [5] provide a diverse set of supply disruption examples, proving that ignoring the possibility of supply chain disruptions can have devastating economic consequences. Yu and Qi [11] present a thorough coverage of how disruption management concept is applied and what impact it makes.

Our study is particularly related to studies that focus on supply disruption (for reviews, see Tang [7] and Snyder et al. [12]). Based on a summary of relevant supply chain risk categories done by Heckmann et al. [13], supply disruption is regarded as a type of network risk. As we have mentioned earlier, in practice, various operational tools can be used to leverage supply disruptions, such as multi-sourcing, carrying inventory, alternative supply sources and backup production options, mutual assistance and contract design and coordination.

A large body of literature studies multi-sourcing, carrying inventory and backup production to hedge against supply disruption. Most such studies are from the perspective of the buyer, and consider the ex ante decisions, such as supplier selection, order allocation, pricing and sourcing strategy. Tomlin [14] focuses on the supply-side tactics (sourcing mitigation, inventory mitigation, and contingent rerouting) when the manufacturer can source from two suppliers, one is unreliable and the other is reliable but more expensive. He finds that inventory mitigation is not an attractive strategy when the disruption occurs rarely but lasts a long time. Babich et al. [15] establish a one-period model of a supply chain with one retailer and multiple risky suppliers to study the problems of supplier selection, pricing, and ordering policies among firms. Zeng and Xia [16] discuss the interactions between the purchasing firm and the backup supplier and the backup supply contract design problem. Yang et al. [17] consider the supplier selection to either pay a penalty to the manufacturer for the shortfall or use backup 
production to fulfill the manufacturer's order once disruption occurs. Huang and $\mathrm{Xu}$ [18] investigate the coexistence and exclusivity of dual sourcing and backup production. Tomlin and Snyder [19] consider a threat advisory system in which the firm, operating a periodic-review inventory system, sources from an unreliable supplier, for which inventory is the only disruption-management tactic, and then extend their model to the situation in which the firm can source from two suppliers. They characterize the optimal threat-dependent inventory levels and show that a threat advisory system can result in substantial cost savings. Sawik [20] uses VaR and CVaR to study the supplier selection and order allocation in make-to-order environment in the presence of supply chain disruption risks. $\mathrm{Hu}$ and Kostamis [21] investigate a manufacturer's optimal multiple-sourcing strategies, and show that the optimal unreliable orders are ranked by a simple and intuitive criterion, and are invariant of minor market size changes.

Increased attention has been paid to mutual assistance between upstream and downstream partners, such as financial assistance, price and/or quantity incentives. First, the financial problems of suppliers can lead to supply disruption; hence, manufacturers may use financial means, such as financial subsidies, to alleviate the financial state of the supplier. Babich [22] uses a dynamic, stochastic, periodic-review model to examine both the optimal joint capacity ordering and financial subsidy policy for the manufacturer, demonstrating the process by which a manufacturer can bring down its supply risk by providing financial subsidies to suppliers. Wadecki et al. [23] modify Babich's model by considering competition among manufacturers and the use of dedicated or shared suppliers among them, and by analyzing the optimal subsidy decisions of manufacturers in four supply chain structures. They also examine the impact of manufacturer-level competition on subsidies and the effect of yield uncertainty on the consumer surplus. Tang et al. [10] consider that buyers can offer either direct (investment subsidy) or indirect (inflated order quantity) incentives to their preferred supplier to improve its process reliability, and find that for the all-or-nothing model, the buyer prefers to only use the subsidy option, but in the partial disruption model, both incentives — subsidy and order inflation — may be used at the same time. Second, once supply disruption occurs, the buyer may use price and/or quantity levers to provide incentives to the supplier and facilitate restoration investment. Hu et al. [24] focus on how the buyer can use price and/or quantity incentives to motivate supplier investment in capacity restoration and restoration effort after disruption; they then compare this approach with a supplier diversification strategy.

Contract design under disruption risk also plays a prominent role in the risk management of a 
buyer. Much of current work focuses on pricing strategies and order allocation in the multi-suppliers system. The choice between short-term and long-term contracts and dynamic contracts when the default risk of suppliers is endogenous are explored in [25]. However, few papers consider the production recovery of the supplier (restoration recovery) and the non-delivery penalty decision of the buyer in the contract. Iyer et al. [26] assume that the backorder cost of the buyers is private information, and that the cost of restoration depends on the speed with which it has been completed. They also study the upfront investment of the supplier during regular periods and optimal contract structure. Non-delivery penalty and financial assistance distinguish our research from their study. Gurani and Shi [27] , meanwhile, use a Nash bargaining game to compute the optimal contract price and quantity of trade, as well as to discuss the role of using down-payment or non-delivery penalty in the contract. However, the non-delivery penalty is not a decision variable in that work. Shou et al. [28] establish two competing supply chains, each of which consists of one retailer and one supplier. They also consider two types of contracts, namely, the revenue sharing contract and the wholesale-price contract with linear penalty for supply disruption, after which they characterize their optimal contract terms under supply uncertainty.

The above supply disruption problems belong to the field of enterprise risk management (ERM) [29]. Enterprise risk may come from a variety of factors with potential impact on business operations, especially on supply chains [30]. Based on Wu et al. [30], Choi et al. [31] summarize the enterprise risks source: external risks, internal risks and procedural risks. For example, external risks consist of regulatory risk, market risk and partner risk, and internal risks include human resource, technological risk, financial risk etc. Supply disruption is a type of partner risk. ERM takes a systematic approach to risk management in organizations, including identification, analysis and either acceptance or mitigation of uncertainty in investment decision making [29]. Hoyt and Liebenberg [32] find a positive relation between firm value and the use of ERM. Wu et al. [33] provide a review on the use of business intelligence in the ERM. Choi et al. [31] offer an excellent review on ERM and identify pioneer work and pioneer scholars. They review and conduct critical analysis of the work of Wu and Olson [30]. The current researches mainly focus on the ERM framework ([30], [34]), the benefit of ERM ([32]), the techniques of ERM ([35], [36]) and the organizational dynamics of the ERM ([37]). Our work falls into ERM by focusing on how to use effective strategies to mitigate the impact of substantial enterprise risk on participators of supply chain. The study on ERM focuses on enterprise risk-mitigation management, whereas in this paper, mutual assistance between partners happens after the realization of supply 
disruption, therefore, it is used as a contingency tactic. Furthermore, Stackelberg game has been widely used to discuss supply chain problems [38], such as supply chain coordination (Qi et al. [39]), supply chain disruption (Tang et al. [10]). This paper uses Stackelberg game to cope with supply disruption problem which is an important topic in ERM. We choose part of some classical researches which focus on different operational tools to deal with supply disruption to highlight the contributions of this paper (see Table 1).

Table 1. The literature positioning of this paper

\begin{tabular}{|c|c|c|c|c|c|c|}
\hline Operational Tools & Research & $\begin{array}{l}\text { Decision } \\
\text { Maker }\end{array}$ & $\begin{array}{c}\text { Ex-post } \\
\text { Decisions }\end{array}$ & $\begin{array}{l}\text { Non-delivery } \\
\text { Penalty } \\
\text { Decision }\end{array}$ & $\begin{array}{c}\text { Capital } \\
\text { Constraint }\end{array}$ & $\begin{array}{l}\text { Production } \\
\text { Recovery }\end{array}$ \\
\hline Multi-sourcing & $\mathrm{Hu}$ and Kostamis [21] & Manufacturer & $x$ & $x$ & $x$ & $x$ \\
\hline Carrying Inventory & Tomlin and Snyder [19] & Buyer & $x$ & $x$ & $x$ & $x$ \\
\hline Backup Production & Yang et al.[17] & $\begin{array}{l}\text { Supplier and } \\
\text { manufacturer }\end{array}$ & $x$ & $\sqrt{ }$ & $x$ & $x$ \\
\hline Contract Design & Gurani and Shi [27] & $\begin{array}{c}\text { Supplier and } \\
\text { buyer }\end{array}$ & $x$ & $\sqrt{ }$ & $x$ & $x$ \\
\hline \multirow[t]{2}{*}{ Mutual Assistance } & $\begin{array}{l}\text { Babich[22] } \\
\text { Tang et al. [10] }\end{array}$ & $\begin{array}{c}\text { Supplier } \\
\text { and/or } \\
\text { manufacturer } \\
\text { (buyer) }\end{array}$ & $x$ & $x$ & $\sqrt{ }$ & $x$ \\
\hline & This paper & $\begin{array}{l}\text { Supplier and } \\
\text { manufacturer }\end{array}$ & $\sqrt{ }$ & $\sqrt{ }$ & $\sqrt{ }$ & $\sqrt{ }$ \\
\hline
\end{tabular}

This paper is different from the existence researches. First, unlike the paper studying supply disruption from the manufacturer's perspective, our study has a more comprehensive scope including the production recovery decision of a supplier after supply disruption, the penalty decision of the manufacturer before supply disruption, and the financial assistance provided by the manufacturer to help the capital-constrained supplier in disruption management. Second, except $\mathrm{Hu}$ et al. [24], the researches on mutual assistance in the presence of supply chain disruption ignore the supplier's production recovery (restoration recovery) after supply disruption. More importantly, different from 
mutual assistance shown in other studies, in our study, the manufacturer loans money to the supplier in order to provide incentive to the supplier or sets the penalty of non-delivery in the contract. Third, in the field of ERM, many risk management tools have been used to deal with enterprise risk. Financial assistance between supply chain enterprises, production recovery and Stackelberg game between the manufacturer and the supplier distinguish our study from the existing works on ERM. Finally, we pay attention to the use of ex-post strategy to protect the firm's profit.

\section{The Model}

We consider a one-period make-to-order supply chain with a risk-neutral supplier (he) and a risk-neutral manufacturer (she). The manufacturer purchases a single product from the supplier and resells it to a market with a demand $D$, which follows a cumulative probability distribution $F(\cdot)$ and density probability distribution $f(\cdot)$. Let $\bar{F}(\cdot)=1-F(\cdot)$ and $\mu=E(D)$. In line with Cachon [40], we assume $F(\cdot)$ is a strictly increasing and differentiable function with $F(0)=0$. The manufacturer orders from the supplier at a unit cost $c_{r}$ before the demand $D$ is realized. The market price that the manufacturer faces is $p$. For the supplier, the production cost per unit is $c_{s}$ in the state of no supply disruption. The unit salvage price for any overstock is $v$, where $v<c_{r}$.

In the state of no disruption, the supplier can meet the manufacturer's order and then finish the contract signed by the manufacturer and the supplier. However, the supplier's production process is subject to a disruption with probability $\rho$. When a disruption happens, the supplier exerts efforts to recover his production and may deliver fewer products than that the manufacturer has ordered.

To prevent significant profit loss from supply disruption and compel the supplier to resume production as soon as possible, the supplier will pay a penalty to the manufacturer as agreed in the contract. Once a supply disruption happens, however, the supplier may be capital-constrained, and the manufacturer may offer financial assistance to the supplier (i.e., lending money to the supplier).

The manufacturer can adopt three strategies to deal with a supply disruption: an ex-ante penalty strategy (PS) with the penalty, an ex-post financial assistance strategy (FAS) with a loan to the supplier, or a mixed strategy (MS) with a penalty and FAS. The sequence of events under different strategies is shown in Figure 1. 

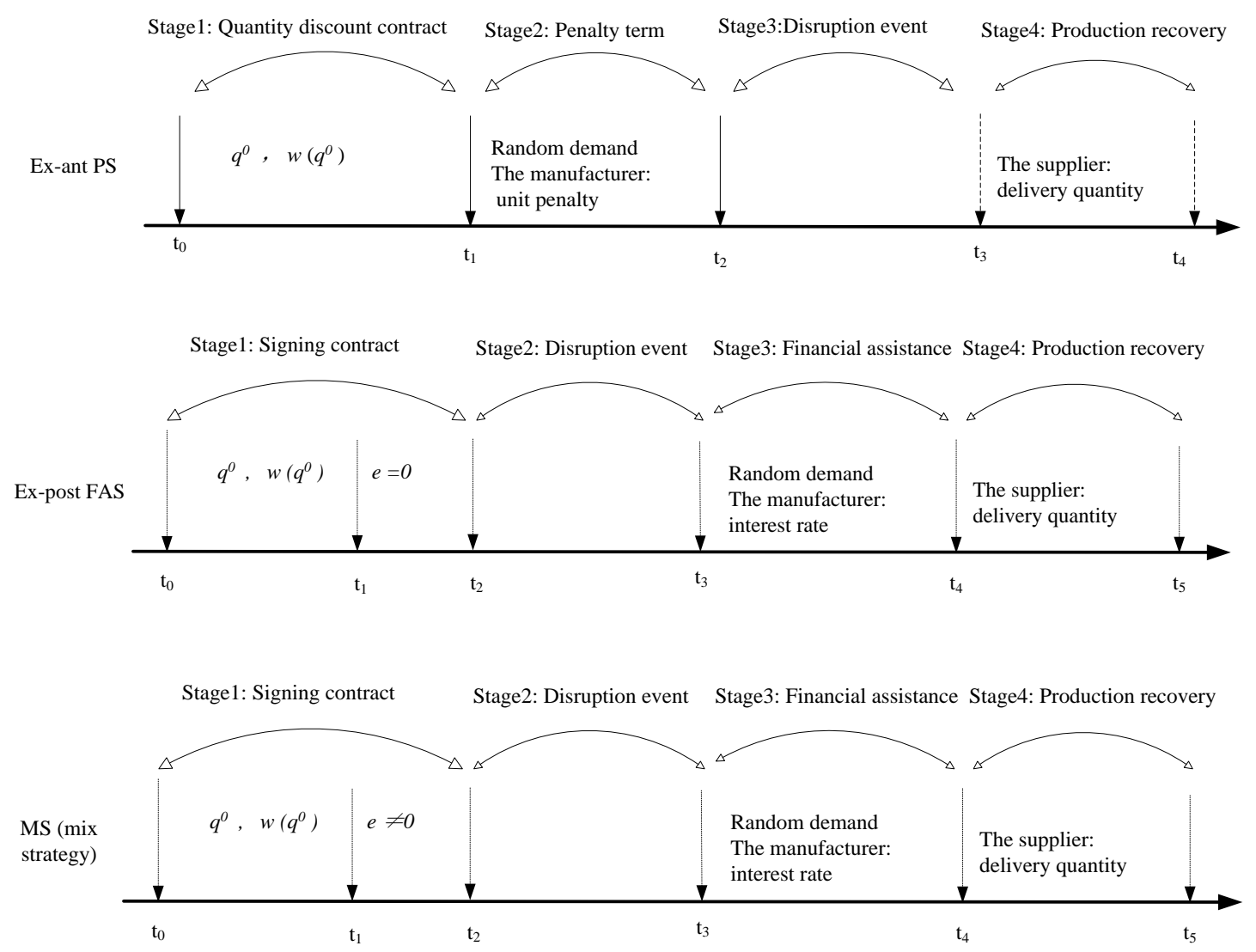

Figure 1. Sequence of events under three strategies

In PS, at Stage 1, the supply chain is coordinated through a quantity discount contract, where the supplier delivers $q^{0}$ units of the product to the manufacturer at the price $w\left(q^{0}\right)$ during the contract period $T$. At Stage 2, the manufacturer determines the unit penalty $e(e \geq 0)$, if the supplier fails to fulfill the full order because of disruption. Supposing a disruption does occur at Stage 3, the supplier decides the recovery effort $z$ conditional on a (partially) recovered production capacity at Stage 4 .

In PS, we consider two different decision-making scenarios, centralized and decentralized. In the centralized decision making, the objective of the centralized decision maker is to maximize the profit of the whole supply chain. In the decentralized decision making, the participants of the supply chain maximize their individual profits, respectively.

In both FAS and MS, at Stage 1, the manufacturer signs a quantity discount contract with the supplier, simultaneously determining the wholesale price $w\left(q^{0}\right)$, the order quantity $q^{0}$, the contract period $T$, and the unit penalty $e$. If a disruption happens, the manufacturer may then offer a loan to the supplier and set an interest rate $\alpha$ at Stage 3. At Stage 4, the supplier exerts production recovery effort and decides the recovery effort $z$. In FAS, the unit penalty is zero, which means that the 
manufacturer does not ask the supplier to pay non-delivery penalty. The MS strategy is similar to the FAS, but differs in that both the financial assistance and the penalty are considered simultaneously in the MS.

To model the supplier's production process, we assume the supplier produces the product at the rate of $q^{0} / T$ per time unit in the normal state designated for on-time delivery. Suppose that the quantity discount contract goes into effect at time 0 . At time $t=t_{2}\left(0 \leq t_{2}<T\right)$, the supplier is subject to a disruption resulting from a non-force majeure event, causing the production rate to immediately fall to 0 (e.g., the Philips semiconductor plant shut down because of a fire). At the same time, the supplier starts to recover his production. For analytical tractability, we let $t_{2}=0$. The recovery time is the time period when the supplier's delivery quantity equals the order quantity $q^{0}$. Since the supplier delivers the products produced during the recovery period at the end of the contract $(T)$, the recovery time should be as long as possible; otherwise, the storage cost will emerge. Furthermore, given the order quantity $q^{0}$, the recovery cost/effort decreases as the recovery time increases. The recovery time thus should be the contract time which is the maximum time for the production recovery. The supplier then uses emergency resource to recover the production, where the unit production cost $c_{e}$ is higher than that of normal state because of extra resources investment (i.e., $c_{e}>c_{s}$ ). If more resources are invested to recover the production, the production rate will be recovered more quickly, and then the supplier will deliver more products to the manufacturer within the contract period. Thus, we define $z=c_{e}-c_{s}$ as the recovery effort that affects the recovery of the production rate, and finally determines the delivery quantity.

One practical case is that the production rate is recovered progressively over time. To model such a case, let the production rate at time $t$ be modeled by $\theta=g(k, z, t)$, which refers to the increase of the values of $k, z$ and $t$. Here $k$ is a fixed production recovery coefficient, which can be interpreted as the basic factors related to the disruption management of the supplier (e.g., flexibility, preventive measures, and the quality of the machines). To focus on the essential factors, such as penalty terms and financial assistance, we assume that the recovered production rate is a linear function of unit production cost $z$ and $t$, i.e., the production rate at time $t$ is $k z t$. In such case, the accumulated delivery 
quantity $q$ at time $T$ is $\int_{0}^{T} k z t d t=\frac{1}{2} k\left(c_{e}-c_{s}\right) T^{2}$. Hence, the decision of recovery effort is equivalent to the decision of delivery quantity. In order to obtain some intuitive results, we use the delivery quantity to be the decision of the supplier in the whole paper. For analytical tractability, we assume that the production cost in the case of no disruption is zero, that is, $c_{s}=0$. Thus, the accumulated delivery quantity at time $T$ becomes $q=\frac{1}{2} k c_{e} T^{2}$. If the delivery is less than the order quantity $q^{0}$, then the manufacturer can claim a penalty according to the contract.

To model the capital constraint, we assume that the supplier has some initial cash $R$ to cover the extra expense of recovering the production, such as overtime payment, the cost of repairing damaged machines, and so on. The total cash consumed during the recovery production process is $c_{e} \cdot \frac{1}{2} k c_{e} T^{2}$. We discuss two cases in the following analysis: 1) capital constraint $\left(R<c_{e} \cdot \frac{1}{2} k c_{e} T^{2}\right)$, and 2) no capital constraint ( $R \geq c_{e} \cdot \frac{1}{2} k c_{e} T^{2}$ ). If after the recovery process, the remaining money at time $T$ plus a transfer payment from the manufacturer is less than the penalty to be paid to the manufacturer for delivery shortfall, then the supplier risks financial distress and even bankruptcy. Therefore, we assume that the supplier accepts the contract only under the precondition of not going bankrupt, i.e.,

$$
R+\left(w\left(q^{0}\right)-c_{e}\right) \cdot \frac{1}{2} k c_{e} T^{2}-e \cdot\left(q^{0}-\frac{1}{2} k c_{e} T^{2}\right) \geq 0 .
$$

We list the notation in Table 2.

Table 2. Summary of Key Notations

\section{$D$ : demand}

$F(\cdot) / f(\cdot)$ : distribution/density function of demand $D$

$\mu$ : the mean of demand $D$

$\rho$ : the disruption probability

$c_{r}$ : the manufacturer's marginal cost per unit

$p:$ unit market price

$v:$ unit salvage value of the surplus stock

$c_{s}$ : unit production cost in the case of no disruption $\left(c_{s}=0\right)$

$c_{e}:$ unit production cost in the case of disruption

$q^{0}:$ order quantity of the manufacturer in the contract signed before a disruption occurs 
$w\left(q^{0}\right)$ : wholesale price the supplier sets in the contract signed before a disruption occurs

$T:$ contract period

$e:$ unit non-delivery penalty

$z:$ recovery effort of the supplier after the disruption

$q$ : delivery quantity under a (partially) recovered production capacity

$q_{i}^{*}$ : optimal delivery quantity under ex-ante PS strategy with the penalty $(i=s e) /$ ex-post FAS strategy

$(i=s b)$ or under centralized situation $(i=c e)$

$\theta$ : production rate

$k$ : production recovery coefficient

$\alpha:$ the interest rate given by the manufacturer

$R$ : initial cash of the supplier

$t$ : the time and $0 \leq t \leq T$

\section{The Baseline Case without Disruption}

We first study the benchmark case without disruption. In line with Cachon [41], we assume the supply chain is coordinated with the "all unit" quantity-discount contract. The manufacturer's expected sale, $S(q)$, is thus given by:

$$
S(q)=E(\min \{q, D\})=\int_{0}^{q} x f(x) d x+q \int_{q}^{\infty} f(x) d x=\int_{0}^{q} x d x+q \bar{F}(q) .
$$

We can further obtain that $\int_{0}^{q} x f(x) d x=\int_{0}^{q} x d F(x)=\left.x F(x)\right|_{0} ^{q}-\int_{0}^{q} F(x) d x=q F(q)-\int_{0}^{q} F(x) d x$. Combining the above two equations, we have the following result:

$$
S(q)=E(\min \{q, D\})=q-\int_{0}^{q} F(x) d x .
$$

Let $I(q)$ be the expected left over inventory, so $I(q)=E\left((q-D)^{+}\right)=q-S(q)$.

Define $c=c_{r}+c_{s}$. Then the profit function of the supply chain can be rewritten as

$$
\begin{aligned}
\pi_{s c}(q) & =p S(q)+v I(q)-c q \\
& =(p-v) S(q)-(c-v) q .
\end{aligned}
$$

According to Cachon [41] and Tomlin [42], the supply chain can be coordinated with an "all unit" quantity-discount contract, and the ordering price of the manufacturer is expressed as

$$
w(q)=\left[\left(1-\lambda_{0}\right)(p-v)\right] S(q) / q+\lambda_{0}(c-v)-c_{r}+v,
$$

where the parameter $\lambda_{0}$ is used to allocate the supply chain profit between the supplier and the 
manufacturer. The optimal order quantity is expressed as

$$
q^{0}=F^{-1}\left(\frac{p-c}{p-v}\right)
$$

The profit function of the manufacturer can now be written as

$$
\pi_{m}\left(q^{0}\right)=p S\left(q^{0}\right)+v I\left(q^{0}\right)-\left[w\left(q^{0}\right)+c_{r}\right] q=\lambda_{0} \pi_{s c}\left(q^{0}\right) .
$$

Meanwhile, the profit function of the supplier can be written as

$$
\pi_{s}\left(q^{0}\right)=w\left(q^{0}\right) q^{0}-c_{s} q^{0}=\left(1-\lambda_{0}\right) \pi_{s c}\left(q^{0}\right) .
$$

Note that other contract types, such as the buy-back contract, the revenue sharing contract, the quantity flexibility contract and the sales rebate contract, can also coordinate the supply chain and redistribute profit among players. Therefore, even if a different contract is adopted, our following analytic results are still valid.

\section{Ex-ante PS with Supply Disruption}

In PS, when the supply is disrupted, the manufacturer does nothing but asks the supplier to pay a penalty for the delivery shortfall at time $T$. Prior to the penalty decision, the supplier and the manufacturer agree to a quantity-discount contract specifying the price and order quantity. Then, the manufacturer determines a unit penalty $e$. After the disruption, the supplier determines the level of production recovery and the corresponding delivery quantity. Both the manufacturer and supplier seek to maximize their respective profits, which can be called "the decentralized decision making".

\subsection{Production recovery decisions made by the supplier}

Given the unit penalty $e$, the optimization problem of the supplier after a disruption, is to optimize $c_{e}$ and $q$, such that

$$
\max \pi_{s e}\left(c_{e}, q\right)=w\left(q^{0}\right) q-c_{e} q-e\left(q^{0}-q\right) .
$$

Given that $q=\frac{k T^{2} c_{e}}{2}$, the objective function of the supplier can now be written as a function of $q$ only, which is expressed as

$$
\pi_{s e}(q)=w\left(q^{0}\right) q-\frac{2 q^{2}}{k T^{2}}-e\left(q^{0}-q\right)
$$

From Eq. (1), we derive the following result. All proofs are attached in the appendix. 
Theorem 1. For any given $e$, the optimal delivery quantity $q_{s e}^{*}$ of the supplier with an initial capital of $R$, is given below

$$
q_{s e}^{*}=\left\{\begin{array}{cc}
\frac{e+w\left(q^{0}\right)}{4} k T^{2} & R \geq \frac{k T^{2}\left(w\left(q^{0}\right)+e\right)^{2}}{8} \text { and } \quad q^{0} \geq \frac{e+w\left(q^{0}\right)}{4} k T^{2} \\
q^{0} & R \geq \frac{\left(\sqrt{2} q^{0}\right)^{2}}{k T^{2}} \text { and } \quad q^{0} \leq \frac{e+w\left(q^{0}\right)}{4} k T^{2} \\
T \sqrt{\frac{R k}{2}} & R<\frac{k T^{2}\left(w\left(q^{0}\right)+e\right)^{2}}{8} \text { and } q^{0}>\frac{e+w\left(q^{0}\right)}{4} k T^{2} \\
\text { or } R<\frac{\left(\sqrt{2} q^{0}\right)^{2}}{k T^{2}} \text { and } \quad q^{0}<\frac{e+w\left(q^{0}\right)}{4} k T^{2}
\end{array} .\right.
$$

Here $\frac{e+w\left(q^{0}\right)}{4} k T^{2}$ is the optimal delivery quantity without capital constraint. We consider two cases: Case I: $q^{0} \geq \frac{e+w\left(q^{0}\right)}{4} k T^{2}$; Case II: $q^{0}<\frac{e+w\left(q^{0}\right)}{4} k T^{2}$. Figure 2 depicts Theorem 1 intuitively.

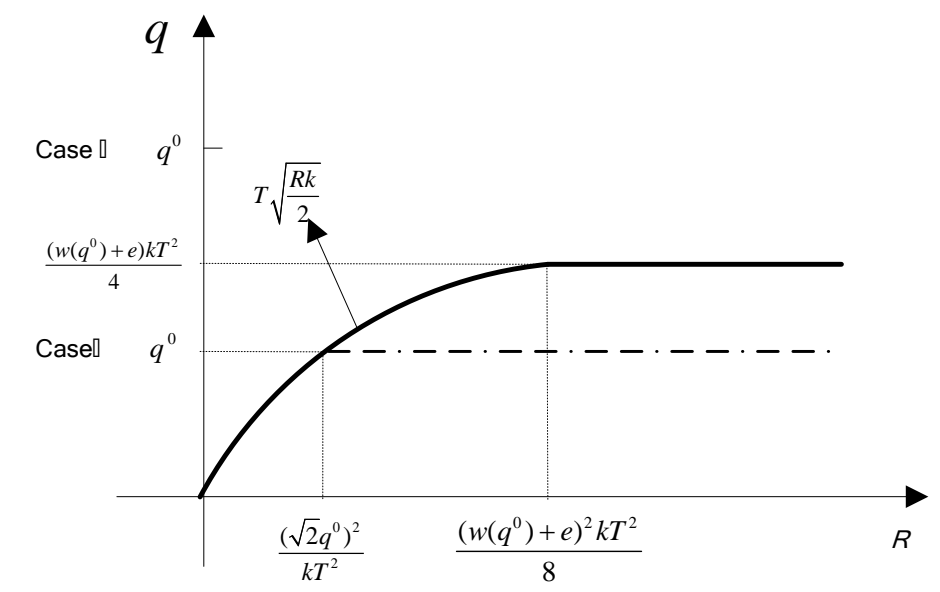

Figure 2. Optimal delivery quantity for the supplier at different $R$ levels

The above theorem shows that, as the initial capital $R$ is sufficiently large, the supplier's delivery quantity increases with the penalty level $e$ until $q^{0}$ is achieved. This result indicates that the penalty can effectively force the supplier to increase the recovery effort. However, when $R$ is small, the delivery quantity becomes constant relative to the penalty term $e$. In other words, the penalty is not always helpful for the manufacturer to receive the contracted quantity $q^{0}$ if the supplier does not have sufficient capital. Overall, the supplier should take the capital constraint into consideration when determining the level of $e$, because the lack of cash can lead to the failure of the optimal delivery quantity policy. 
When $e>\frac{4 q^{0}}{k T^{2}}-w\left(q^{0}\right)$, Theorem 1 shows that the supplier will have a fixed delivery quantity at either $q^{0}$ or $T \sqrt{\frac{R k}{2}}$, depending on the initial capital $R$ of the supplier. A larger $e$ cannot push the supplier to change his behavior. In the case of delivery quantity at $q^{0}$, the disruption has been fully recovered and any higher penalty cannot induce any higher recovery effort. Meanwhile, in the case of delivery quantity at $T \sqrt{\frac{R k}{2}}$, the supplier has used his full capital and any higher penalty cannot result in more delivery. Thus, in the following parts of this paper, we only discuss the case with $e \leq \frac{4 q^{0}}{k T^{2}}-w\left(q^{0}\right)$, and $q_{s e}^{*}$ in Theorem 1 can be rewritten as

$$
q_{s e}^{*}=\left\{\begin{array}{ll}
\frac{e+w\left(q^{0}\right)}{4} k T^{2} & R \geq \frac{k T^{2}\left(w\left(q^{0}\right)+e\right)^{2}}{8} \\
T \sqrt{\frac{R k}{2}} & R<\frac{k T^{2}\left(w\left(q^{0}\right)+e\right)^{2}}{8}
\end{array} .\right.
$$

According to Eq.(2), we define two cases, high penalty (HP) and low penalty (LP), where HP refers to $e>\sqrt{\frac{8 R}{k T^{2}}}-w\left(q^{0}\right)$ and LP refers to $e \leq \sqrt{\frac{8 R}{k T^{2}}}-w\left(q^{0}\right)$. In the case of HP, the supplier exhausts all initial capital for production recovery, while in the case of LP, the delivery quantity of the supplier depends on the unit penalty of the manufacturer. Thus, $\sqrt{\frac{8 R}{k T^{2}}}-w\left(q^{0}\right)$ is the point at which the supplier changes his action.

Lemma 1. When $R<\frac{2}{k T^{2}}\left[\frac{e}{w\left(q^{0}\right)+e} q^{0}\right]^{2}$, the supplier becomes bankrupt. Furthermore, as the unit penalty $e$ increases or $T$ decreases, the bankruptcy risk increases.

Lemma 1 shows that when the supplier is capital-constrained, the longer the time taken to meet contractual obligations, the lower the bankruptcy risk becomes. Hence, the penalty also has an effect on the bankruptcy risk level.

\subsection{The penalty decision of the manufacturer}

This section considers the manufacturer's penalty selection. We discuss the respective penalty 
decisions of the manufacturer in HP (i.e., $e>\sqrt{\frac{8 R}{k T^{2}}}-w\left(q^{0}\right)$ ) and LP (i.e., $e \leq \sqrt{\frac{8 R}{k T^{2}}}-w\left(q^{0}\right)$ ) cases, respectively.

In the case of HP, the supplier with the initial capital $R$ yields the delivery quantity of $T \sqrt{\frac{R k}{2}}$, and as such, from the manufacturer's perspective, there is an opportunity to extract a large amount of penalty by setting the penalty term $e$ to be very large. However, from Lemma 1 , if $R<\frac{2}{k T^{2}}\left[\frac{e}{w\left(q^{0}\right)+e} q^{0}\right]^{2}$, the supplier rejects the contract because he may go into bankruptcy as the effect of the disruption. Therefore, the supplier accepts the contract only when $R \geq \frac{2}{k T^{2}}\left[\frac{e}{w\left(q^{0}\right)+e} q^{0}\right]^{2}$. On the other hand, considering the capital constraint condition $R<\frac{k T^{2}\left(w\left(q^{0}\right)+e\right)^{2}}{8}$, which is a prerequisite for the bankruptcy, we can get $\frac{k T^{2}\left(w\left(q^{0}\right)+e\right)^{2}}{8}>\frac{2}{k T^{2}}\left[\frac{e}{w\left(q^{0}\right)+e} q^{0}\right]^{2} \quad$ and $\quad R \quad$ should $\quad$ meet $\quad$ the $\quad$ condition $\frac{k T^{2}\left(w\left(q^{0}\right)+e\right)^{2}}{8}>R \geq \frac{2}{k T^{2}}\left[\frac{e}{w\left(q^{0}\right)+e} q^{0}\right]^{2}$ for the supplier to accept the contract. The condition can be rewritten as $\sqrt{\frac{8 R}{k T^{2}}}-w\left(q^{0}\right)<e \leq \frac{w\left(q^{0}\right) \sqrt{R k T^{2}}}{\sqrt{2} q^{0}-\sqrt{R k T^{2}}}$. Therefore, if the unit penalty $e$ is in the region $\left(\sqrt{\frac{8 R}{k T^{2}}}-w\left(q^{0}\right), \frac{w\left(q^{0}\right) \sqrt{R k T^{2}}}{\sqrt{2} q^{0}-\sqrt{R k T^{2}}}\right]$, then the supplier produces and delivers $T \sqrt{\frac{R k}{2}}$ units with no bankruptcy risk. Thus, the optimal unit penalty $e$ becomes $\frac{w\left(q^{0}\right) \sqrt{R k T^{2}}}{\sqrt{2} q^{0}-\sqrt{R k T^{2}}}$.

The above analysis leads to Theorem 2 .

Theorem 2. In the case of HP, the optimal unit penalty to the manufacturer is $e^{*}=\frac{w\left(q^{0}\right) \sqrt{R k T^{2}}}{\sqrt{2} q^{0}-\sqrt{R k T^{2}}}$.

In reality, the high penalty can urge the supplier to increase his production, reducing the negative impact of supply disruption; however, an oppressive penalty clause may lead to a greater risk faced by the supplier, especially for a capital-constrained one. Once the disruption happens, the supplier may 
suffer catastrophic losses, which can lead to bankruptcy, so the manufacturer must give a suitable penalty for long-term trade relationship. Thus, the study on decisions of two firms in the case of LP has more practical significance.

In the case of LP, the response of the supplier depends on the penalty. Consequently, the manufacturer determines $e$ to maximize her expected profit, which is expressed as

$$
\begin{aligned}
\pi_{r e}(e) & =\rho\left[p S\left(q_{s e}^{*}(e)\right)+v I\left(q_{s e}^{*}(e)\right)-\left(w\left(q^{0}\right)+c_{r}\right) q_{s e}^{*}(e)+e\left(q^{0}-q_{s e}^{*}(e)\right)\right]+(1-\rho) \lambda_{0} \pi_{s c}\left(q^{0}\right) \\
& =\rho\left[(p-v) S\left(q_{s e}^{*}(e)\right)-\left(w\left(q^{0}\right)+c_{r}-v\right) q_{s e}^{*}(e)+e\left(q^{0}-q_{s e}^{*}(e)\right)\right]+(1-\rho) \lambda_{0} \pi_{s c}\left(q^{0}\right)
\end{aligned}
$$

Theorem 3. In the case of LP, a unique equilibrium point $e^{*}$ is given by

$$
e^{*}=\min \left\{\frac{(p-v) \bar{F}\left(q_{s e}^{*}\left(e^{*}\right)\right)+4 q^{0} / k T^{2}+\left(v-c_{r}\right)}{2}-w\left(q^{0}\right), \sqrt{\frac{8 R}{k T^{2}}}-w\left(q^{0}\right)\right\},
$$

where $q_{s e}^{*}\left(e^{*}\right)=\frac{e^{*}+w\left(q^{0}\right)}{4} k T^{2}$

Theorem 3 states that only if the unit penalty is in the region $\left(0, \sqrt{\frac{8 R}{k T^{2}}}-w\left(q^{0}\right)\right]$ can the manufacturer manipulate the production behavior of the supplier (using the penalty), thus protecting and maximizing her profit. Theorem 3 also shows that the penalty decision is not affected by the probability of disruptions. The reason is that only when the disruption occurs does the manufacturer's profit depend on the penalty decision (see Eq.(3)). Otherwise, when the disruption does not occur, the profit of the manufacturer is constant.

Lemma 2. The optimal unit penalty is decreasing in the contract period $T$ for the case of LP, and increasing in $T$ for the case of $H P$.

Lemma 2 shows that in the case of LP, if the supplier has more time to recover his production, then the manufacturer will set a lower unit penalty. In the case of HP, we know from Lemma 1 that the bankruptcy risk decreases due to the increase of $T$, so if the supplier is unable to increase the delivery quantity due to its being capital-constrained, then the manufacturer can maximize her profit by increasing the unit penalty $e$. The manufacturer can even make her profit bigger than that when there is no disruption, which is referred to as "opportunism behavior."

Lemma 3. The optimal unit penalty increases with $q^{0}$ in LP and decreases in $q^{0}$ in $H P$, respectively. 
Lemma 3 indicates that in the case of LP, the bankruptcy risk the supplier faces increases as $q^{0}$ increases, because from Lemma 1 , if $R<\frac{2}{k T^{2}}\left[\frac{e}{w\left(q^{0}\right)+e} q^{0}\right]^{2}$, that is, $e>\frac{w\left(q^{0}\right) \sqrt{R k T^{2}}}{\sqrt{2} q^{0}-\sqrt{R k T^{2}}}$, the supplier becomes bankrupt. In other words, the increase of the quantity $q^{0}$ will make the manufacturer set a higher unit penalty in the case of LP, and then the supplier is more likely to enter bankruptcy.

\subsection{Centralized decision-making with supply disruption}

In the centralized situation, the supply chain is managed by a central decision-maker whose objective is to maximize the profit of the whole supply chain.

Given the delivery quantity $q$, the centralized supply chain profit under a disruption is written as

$$
\begin{aligned}
\pi_{c e}(q) & =p S(q)+v I(q)-\left(c_{e}+c_{r}\right) q \\
& =(p-v) S(q)-\left(c_{e}+c_{r}-v\right) q,
\end{aligned}
$$

where $c_{e}=\frac{2 q}{k T^{2}}$.

Theorem 4. Given $R$ and $\hat{q}_{c e}$, where $(p-v) \bar{F}\left(\hat{q}_{c e}\right)=\frac{4}{k T^{2}} \hat{q}_{c e}+c_{r}-v$, for a centralized supply chain, the optimal delivery quantity is

$$
q_{c e}^{*}=\left\{\begin{array}{ll}
\hat{q}_{c e} & R \geq \frac{2 \hat{q}_{c e}^{2}}{k T^{2}} \\
T \sqrt{\frac{R k}{2}} & \text { otherwise }
\end{array} .\right.
$$

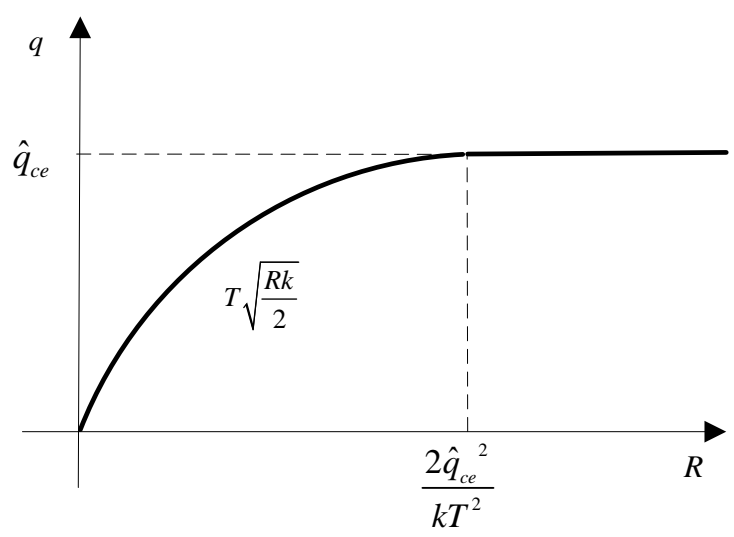

Figure 3. The optimal delivery quantity at different $R$ levels

Similar to Jing et al. [43] and Cai et al., [44], Theorem 4 shows that in the centralized decision-making setting, the internal cash of the supplier may be not sufficient to support optimal 
production. This means that the supplier's financial situation may affect the production of the entire supply chain in the presence of disruption. Thus, if the other members of the supply chain can help the supplier solve the financial problem, the competitive advantage of the supply chain is improved.

Lemma 4. The optimal delivery quantity of the centralized supply chain under a supply disruption is less than that without disruptions, i.e., $q_{c e}^{*}<q^{0}$, when the supplier is not capital-constrained, i.e., $R \geq \frac{2 \hat{q}_{c e}^{2}}{k T^{2}}$

Lemma 4 states that the quantity of the delivered products under a disruption is less than that without disruption because the response to supply disruption changes the production cost. Therefore, the whole supply chain profit is hurt if the supplier produces and delivers as stated in the order. If the manufacturer seeks to maximize the total supply chain profit, she should initiate some measures to motivate the supplier to produce $q_{c e}^{*}$ units, not the order quantity $q^{0}$.

Theorem 4 shows that the optimal delivery quantity maximizing the profit of supply chain is $q_{c e}^{*}$. However, in the decentralized case, how does the manufacturer set a penalty which can achieve the maximum profit for the entire supply chain? In other words, how does a penalty make $q_{s e}^{*}(e)=q_{c e}^{*}$ ? Thus, we get the following Theorem 5 .

Theorem 5. When $e=e^{0}$ and $R \geq \frac{2 \hat{q}_{c e}{ }^{2}}{k T^{2}}, q_{s e}^{*}=q_{c e}^{*}$ for the supplier without capital constraint, where $e^{0}=\frac{4}{k T^{2}} q_{c e}^{*}-w\left(q^{0}\right)$; hence, the supply chain under a supply disruption achieves maximum profit.

Theorem 5 indicates that the manufacturer constrains the behavior of the supplier by setting the unit penalty $e$. However, the capital state of the supplier should be considered.

\section{MS with Supply Disruption}

Having analyzed the ex-ante PS in the decentralized and centralized situations with supply disruption, we now turn our attention to the MS. To help the supplier to deal with his capital problems, the manufacturer may offer financial assistance. This means that the manufacturer loans money to the 
supplier at a reasonable interest rate. This solution helps the supplier effectively handle the disruption and enables the manufacturer to avoid more problems, such as searching for new suppliers, being out of stock, changing its sales planning, and so on.

In this case, the manufacturer proposes an interest rate to the supplier, who then decides whether to accept the assistance. At this point, the supplier also decides on how many products to be produced. Upon the acceptance of assistance, the unit product cost $c_{e}$ is financed by two streams of cash, $c_{e}=c_{0}+c_{1}$, where $c_{0}$ comes from the supplier's own capital in unit production cost, and $c_{1}$ comes from the debt, which has a total of $B=c_{1} q$. Let $\alpha(0<\alpha<1)$ be the interest rate. Then the total interest paid to the manufacturer is $c_{1} q \alpha$.

From previous discussion, we know that the relationship between $c_{e}$ and $q$ is given by $c_{e}=\frac{2 q}{k T^{2}}$. The profit function of the supplier is given by

$$
\pi_{s b}(q)=w\left(q^{0}\right) q-c_{e} q-e\left(q^{0}-q\right)-\left(c_{e}-c_{0}\right) q \alpha
$$

Substituting $c_{e}=\frac{2 q}{k T^{2}}$ into the profit function of the supplier, we have

$$
\pi_{s b}(q)=w\left(q^{0}\right) q-\frac{2 q^{2}}{k T^{2}}-e\left(q^{0}-q\right)-\frac{2 q^{2}}{k T^{2}} \alpha+c_{0} q \alpha
$$

From Theorem 1, we know that when $q_{s e}^{*}<q^{0}$ and $R \geq \frac{k T^{2}\left(w\left(q^{0}\right)+e\right)^{2}}{8}$, the supplier has enough cash to achieve the optimal delivery quantity. In this case, financial assistance is not necessary. Our following focus is to identify when the manufacturer offers the financial assistance and how this affects the production of the supplier when $R<\frac{k T^{2}\left(w\left(q^{0}\right)+e\right)^{2}}{8}$. The theorems below address this concern.

Theorem 6. 1) If $\frac{2 q_{L}^{2}}{k T^{2}} \leq R<\frac{k T^{2}\left(w\left(q^{0}\right)+e\right)^{2}}{8}$, then the supplier does not accept the financial assistance, and the optimal delivery quantity is $q_{s b}^{*}=T \sqrt{\frac{R k}{2}}$;

2) If $R<\frac{2 q_{L}^{2}}{k T^{2}}$, then the supplier accepts the financial assistance, and the optimal delivery quantity 
$q_{s b}^{*}$ becomes

$$
q_{s b}^{*}=\hat{q}_{s b}=\frac{w\left(q^{0}\right)+e+c_{0} \alpha}{4(1+\alpha)} k T^{2} .
$$

The optimal debt level $B^{*}$ is

$$
\frac{\left(w\left(q^{0}\right)+e+c_{0} \alpha\right)\left(w\left(q^{0}\right)+e-c_{0} \alpha-2 c_{0}\right)}{8(1+\alpha)^{2}} k T^{2},
$$

where $q_{L}$ is the minimum of delivery quantity which satisfies $\pi_{s b}\left(\hat{q}_{s b}\right)=\pi_{s e}\left(q_{L}\right)$.

From Theorem 6, in the case that the supplier accepts the financial assistance, the optimal delivery quantity increases as $e, T, c_{0}$ or $k$ increase; however, it decreases as $q^{0}$ increases. Thus, the more cash the supplier has, the higher the delivery quantity becomes

Lemma 5. If $R \leq \frac{2 q_{L}^{2}}{k T^{2}}$ and the supplier accepts the financial assistance, then the following situations can occur:

a) $q_{s b}^{*}$ decreases as $\alpha$ increases; and

b) $B^{*}$ decreases as $\alpha$ and $c_{0}$ increase.

Considering the production decision of the supplier, the expected profit function of the manufacturer is given by

$$
\begin{aligned}
& \pi_{r b}(\alpha)=p S\left(q_{s b}^{*}(\alpha)\right)+v I\left(q_{s b}^{*}(\alpha)\right)-\left(w\left(q^{0}\right)+c_{r}\right) q_{s b}^{*}(\alpha)+e\left(q^{0}-q_{s b}^{*}(\alpha)\right)+c_{1} q_{s b}^{*}(\alpha) \alpha \\
& =(p-v) S\left(q_{s b}^{*}(\alpha)\right)-\left(w\left(q^{0}\right)+c_{r}-v\right) q_{s b}^{*}(\alpha)+e\left(q^{0}-q_{s b}^{*}(\alpha)\right)+c_{1} q_{s b}^{*}(\alpha) \alpha
\end{aligned}
$$

where $c_{1}=\frac{2 q_{s b}^{*}}{k T^{2}}-c_{0}$.

Theorem 7. The optimal interest rate $\alpha^{*}\left(0<\alpha^{*}<1\right)$, satisfies the condition expressed as

$$
\frac{3+\alpha^{*}}{1+\alpha^{*}} M^{2}=2 M\left[(p-v) \bar{F}\left(q_{s b}^{*}\right)+v-\left(c_{r}+c_{0}\right)\right]+c_{0}^{2}\left(1+\alpha^{*}\right)^{2},
$$

where $w\left(q^{0}\right)+e-c_{0}=M$.

Lemma 6. As the market price $p$ increases (decreases) during the disruption, the optimal interest rate $\alpha^{*}$ decreases (increases) correspondingly. 
We know from Lemmas 5 and 6 that, if the market price rises in the process of dealing with the disruption, the manufacturer can motivate the supplier to deliver more products by decreasing the interest rate. The cause lies in the fact that the expected loss of shortage increases when the profit margin increases. Thus, it is more important to meet the market demand. On the contrary, if the market price falls, the manufacturer increases the interest rate to motivate the supplier to decrease the delivery quantity. Thus, the MS can help the manufacturer control the output of the supplier while avoiding the risk of volatile prices.

The results in Theorems 6 and 7 can be applied to the ex-post FAS by letting the penalty $e$ being equal to zero. Furthermore, the results in Lemmas 5 and 6 can also be applied to the ex-post FAS given $e=0$.

\section{The Strategy Preference of the Manufacturer}

We now explore the process by which the parameters in the model may influence what kind of disruption management strategies is chose by the manufacturer. This is also discussed from the supplier's perspective. When a supply disruption occurs, there are three strategies which can be chose from: the PS, the FAS, and the MS. Let $e=0$, the optimal decisions in FAS can be given by Theorems 6 and 7. We investigate the effect of a number of key attributes on the preferred strategy. Such attributes include the initial cash of the supplier (as measured by the supplier's own capital in unit production cost $c_{0}$ ), the market price, the demand fluctuation (as measured by the variance of demand $\sigma$ ), the production recovery coefficient, and the coefficient of profit allocation.

Theorems 1 and 6 show that the manufacturer cannot do anything but use the penalty strategy, if $R \geq \frac{k T^{2}\left(w\left(q^{0}\right)+e\right)^{2}}{8}$. This is because in that situation, the supplier is not capital-constrained and the strategic choice problems do not exist. Thus, we only discuss the case $R<\frac{k T^{2}\left(w\left(q^{0}\right)+e\right)^{2}}{8}$ and analyze the strategy choice problem. Because we focus on the capital constraint of the supplier in the recovery process, the initial cash of the supplier must satisfy $R \geq c_{s} q^{0}=0$, which means that there is no capital constraint if there is no disruption. From Theorem 6, we know that the supplier accepts the 
financial assistance when the initial cash is less than $\frac{2 q_{L}{ }^{2}}{k T^{2}}$, the numerical analysis thus is done in the region $R \in\left[0, \frac{2 q_{L}^{2}}{k T^{2}}\right)$. Similar to Hu et al. [24], we assume that the market demand that the manufacturer faces follows a normal distribution with mean $\mu=50$ and standard deviation $\sigma=5$. We use the following parameters in all instances unless otherwise stated: the manufacturer's unit operation cost $c_{r}=4$, the unit production cost in the state of no disruption $c_{s}=0$, the salvage value of inventory $v=3$, the contract period $T=3$, the profit allocation coefficient $\lambda_{0}=0.6$, and the production recovery coefficient $k=0.6$. We let $p=60$ be the market price and evaluate the performance ratio $\mathrm{P}$ and the delivery ratio $\mathrm{Q}$ as

$$
\begin{gathered}
\mathrm{P}_{i}=\frac{\pi_{i e}\left(e^{0}\right)}{\pi_{i b}(\alpha, e)}, \mathrm{P}_{i}^{F}=\frac{\pi_{i b}(\alpha, 0)}{\pi_{i b}\left(\alpha, e^{0}\right)}, \quad i \in\{r, s, c\} \\
\mathrm{Q}=\frac{q_{s e}\left(e^{0}\right)}{q_{s b}(\alpha, e)}, \mathrm{Q}^{F}=\frac{q_{s b}(\alpha, 0)}{q_{s b}\left(\alpha, e^{0}\right)} .
\end{gathered}
$$

The labels $r, s$ and $c$ refer to the manufacturer, the supplier and the supply chain, respectively. Note that $\pi_{i b}(\alpha, 0)$ is the expected profit in FAS when $e=0$. However, if $e \neq 0, \pi_{i b}(\alpha, e)$ is the expected profit in MS. Here, $\pi_{i e}\left(e^{0}\right)$ refers to the expected profit in PS. If $\mathrm{P}_{i}>1(\mathrm{Q}>1)$, then the PS is better than the FAS or the MS; if $\mathrm{P}_{i}<1(\mathrm{Q}<1)$, the preference is to use the FAS or the MS; else, if $\mathrm{P}_{i}=1(\mathrm{Q}=1)$, there is no difference between the FAS and MS. Here, $\mathrm{P}_{i}^{F}$ follows the similar analysis process. 


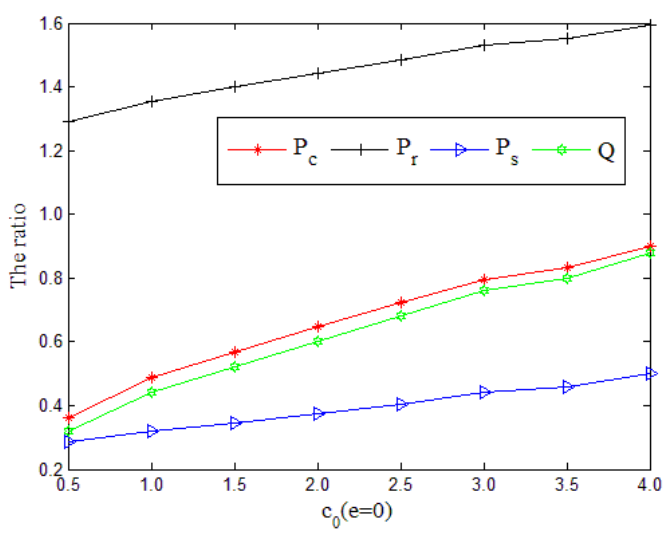

(a) PS vs. FAS

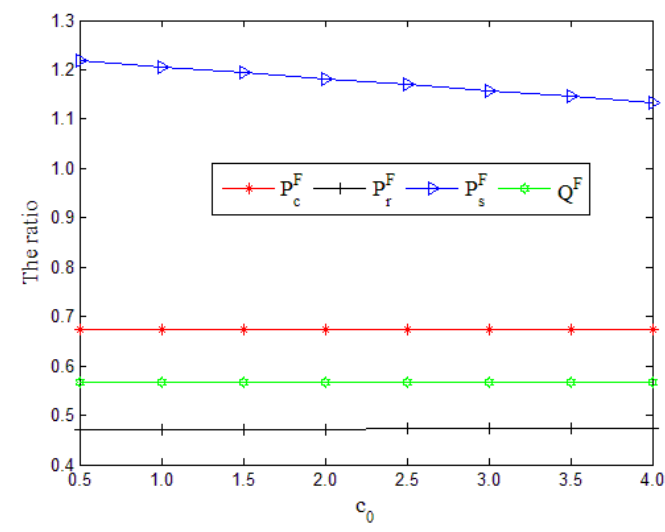

(c) FAS vs. MS

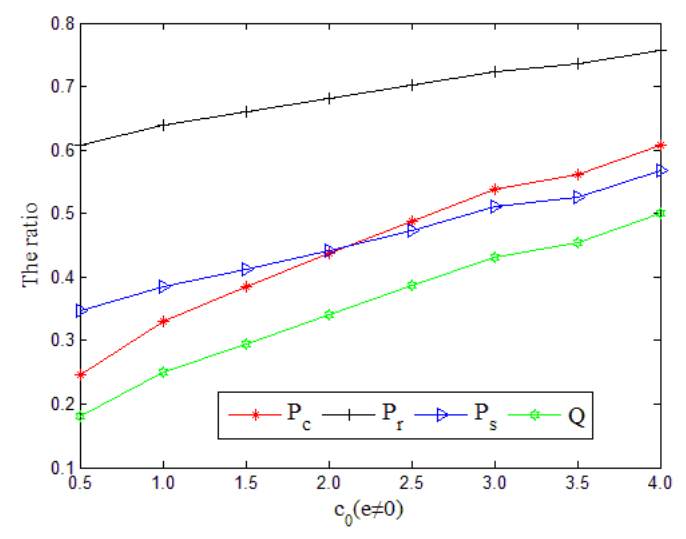

(b) PS vs. MS

Figure 4. The impact of the initial cash of the supplier on the performance ratio and the delivery ratio

The numerical results are summarized in Figure 4, which shows how the initial cash of the supplier influences the performance ratio and the delivery ratio. Figure 4(a) indicates that except for the manufacturer, the FAS dominants PS. It is reasonable because the manufacturer can get more benefits from the penalty than from the interest income and the increase of delivery quantity. For the supplier, both the penalty and the FAS compel him to increase the delivery quantity, but the profit of the supplier is hurt more by the penalty in PS than by the interest payment in FAS, especially when the manufacturer treats the penalty as a kind of income. Therefore, the supplier prefers a financial assistance. The profit of the whole supply chain is better off under the FAS strategy because the delivery quantity in FAS is larger than that in PS. Thus, from the supply chain's perspective, the FAS is preferred.

As Figure 4(b) illustrates, the MS is better than the PS. The MS helps increase the delivery quantity and allows the manufacturer to obtain the interest and penalty income. For the supplier, the financial assistance deals with his capital constraint problem, and then he can produce and deliver more products to the manufacturer, finally gets more revenue and pays less penalty. Figure 4(b) also indicates 
that the preference of the MS decreases with the initial cash.

Figure 4(c) shows that the manufacturer prefers the MS to the FAS, but the supplier has a contrary preference. When there is no capital constraint for the use of financial assistance, the penalty is the only method that can compel the supplier to increase the delivery quantity. Thus, the MS is the preferred strategy in this case. However, for the supplier, the penalty always hurts his profit, so the FAS is better than the MS for the supplier.

From the above analysis, we find that the MS is always the best strategy for the manufacturer. This means that if a supply disruption occurs, the best option for the manufacturer is to offer financial assistance to the capital-constrained supplier, and ask the supplier to pay for the penalty at the end of the contract period. Meanwhile, the FAS is the worst strategy for the manufacturer. Furthermore, the decision objective of the manufacturer has no impact on the strategy preference. However, the supplier has a totally different choice. The FAS is the best strategy, while the PS is the worst strategy. Thus, there is no win-win situation to both the manufacturer and the supplier.

In order to investigate the robust effect on a number of key attributes of the preferred strategy of the manufacturer, we randomly generate 1000 test problem instances from uniform distribution on the given intervals. Table 3 shows the distributions for the data set. The parameters that are not in Table 3 stay the same as before.

Table 3. Distributions of randomly generated data

\begin{tabular}{|c|c|c|c|c|}
\hline Problem data & $p$ & $\sigma$ & $k$ & $\lambda_{0}$ \\
\hline Range & {$[60,80]$} & {$[1,10]$} & {$[0.4,0.7]$} & {$[0.4,0.7]$} \\
\hline
\end{tabular}

Table 4. The robust impact of some key attributes on the performance ratio

\begin{tabular}{|c|c|c|c|}
\hline The rat & $\begin{array}{c}\text { PS vs. FAS } \\
\mathrm{P}_{i}=\frac{\pi_{i e}\left(e^{0}\right)}{\pi_{i b}(\alpha, 0)}<1\end{array}$ & $\begin{array}{c}\text { PS vs. MS } \\
\mathrm{P}_{i}=\frac{\pi_{i e}\left(e^{0}\right)}{\pi_{i b}\left(\alpha, e^{0}\right)}<1\end{array}$ & $\begin{array}{c}\text { FAS vs. MS } \\
\mathrm{P}_{i}^{F}=\frac{\pi_{i b}(\alpha, 0)}{\pi_{i b}\left(\alpha, e^{0}\right)}<1\end{array}$ \\
\hline Supply chain's profit $(i=c)$ & $99.8 \%$ & $100 \%$ & $99.0 \%$ \\
\hline Manufacturer's profit $(i=r)$ & $30.6 \%$ & $100 \%$ & $100 \%$ \\
\hline Supplier's profit $(i=s)$ & $100 \%$ & $100 \%$ & $10.1 \%$ \\
\hline
\end{tabular}


Table 5. The robust impact of some key attributes on the delivery ratio

\begin{tabular}{|c|c|c|c|}
\hline Delivery quantity ratio & $\begin{array}{c}\text { PS vs. FAS } \\
\mathrm{Q}=\frac{q_{s e}\left(e^{0}\right)}{q_{s b}(\alpha, 0)}<1\end{array}$ & $\begin{array}{c}\text { PS vs. MS } \\
\mathrm{Q}=\frac{q_{s e}\left(e^{0}\right)}{q_{s b}\left(\alpha, e^{0}\right)}<1\end{array}$ & $\begin{array}{c}\text { FAS vs. MS } \\
\mathrm{Q}^{F}=\frac{q_{s b}(\alpha, 0)}{q_{s b}\left(\alpha, e^{0}\right)}<1\end{array}$ \\
\hline The percentage & $100 \%$ & $100 \%$ & $99.0 \%$ \\
\hline
\end{tabular}

Table 4 shows that for the supply chain and the supplier, the FAS is better than the PS for $99.8 \%$ and $100 \%$ of the instances, respectively. Table 4 also shows that $69.4 \%$ of instances support the result that the manufacturer prefers the PS strategy. Since the PS has a strong relationship with the initial capital $R$, some small values of $R$ in the region $[0.5,4]$ can reduce the advantage of the PS strategy for the manufacturer. Therefore, the amount of instances which meet $\mathrm{P}_{r}<1$ is a little large. From the delivery quantity's perspective, $100 \%$ of the instances show that the results stay the same.

Tables 4 and 5 also indicate that among 1000 test problem instances, all instances show that the MS is better than the PS. For the supply chain and the manufacturer, $99.0 \%$ and $100 \%$ of the total instances indicate that the MS dominates the FAS, respectively. $89.9 \%$ of the instances show that the supplier has different preference, choosing the FAS rather than the MS. From the delivery's perspective, the result keeps the same for $99.0 \%$ of the instances.

Above results indicate that the strategy preference is robust. This means that for the manufacturer, the MS is adopted as the best strategy in most situations. However, for the supplier, the FAS dominates other strategies in most of situations, and the PS is the worst strategy. The robust characteristic is important for disruption management. This is because the lack of information brought about by the low disruption frequency can increase the complexity of the decisions that must be made as well as reduce the efficiency of such decisions.

\section{Sensitivity Analysis}

In this section, we investigate the impact of $T$ and $p$ on the decisions and profits of both firms. We consider two cases: the one when there is no capital constraint and the other when there is a capital constraint.

Figures 5 and 6 imply that a long-term contract is better than a short-term one for the supplier, because he has enough time to deal with the disruption as a result of small shortage and is bond to pay small amounts of penalties and interest. Furthermore, the differences in the decisions and profits 
between the centralized and decentralized situations become small as $T$ or $p$ increases (see Figure $5)$.

\subsection{Impact of $T$ and $p$ without capital constraint}

The model analysis indicates that the PS is the best strategy for the manufacturer when the supplier is not capital-constrained. All parameters stay the same as those first set in Section 7.

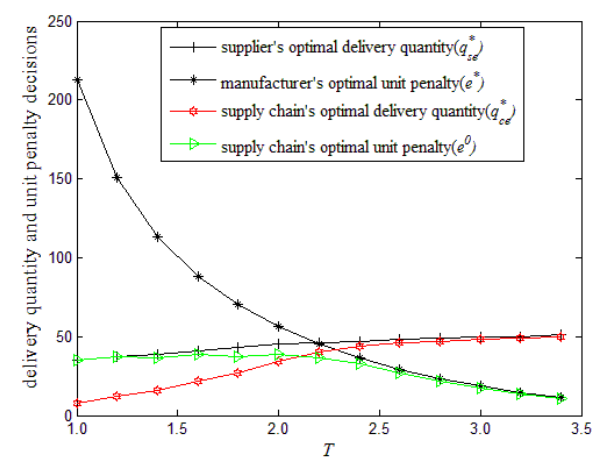

(a) Decisions vs. Contract period

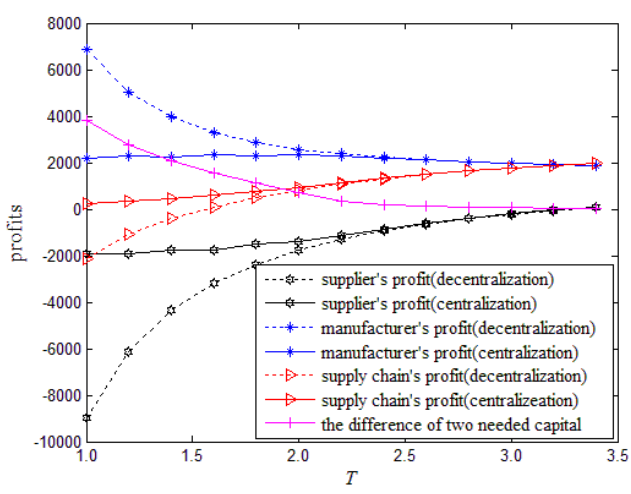

(c) Profits vs. Contract period

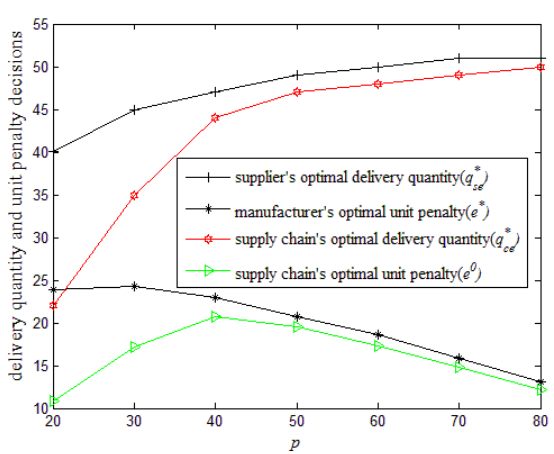

(b) Decisions vs. Market price

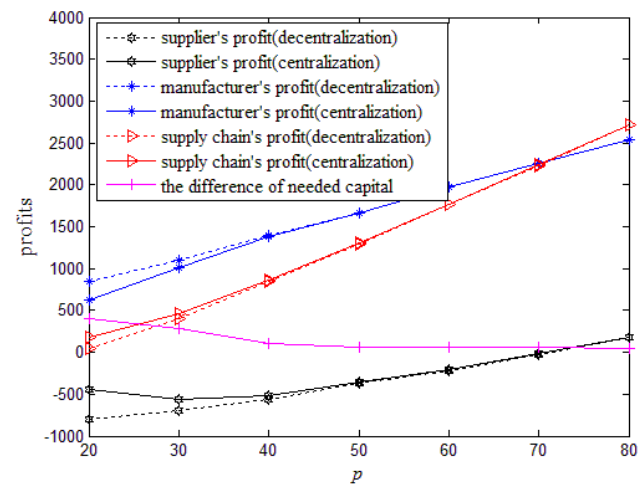

(d) Profits vs. Market price

Figure 5. The impact of $T$ and $p$ on the decisions and the profits of both firms

Figures 5(a) and 5(b) show that the delivery quantity under the centralized decision-making is less than that under the decentralized one, which may be contrary to what is generally expected. So is the unit penalty. In order to verify this result, we randomly generated 1000 test problem instances from the uniform distribution shown in Table 3. About $81.7 \%$ of instances support this result, and the rest do not support the result, which states that $q_{s e}^{*}=q_{c e}^{*}$.

As Figures 5(d) and 5(c) illustrate, the profits of the supplier and the entire supply chain are higher in the case of the centralized decision-making than that under the decentralized decision-making, especially when $T$ is shorter or the price is lower, which means that the centralized decision-making 
plays a significant role in coping with the supply disruption. The manufacturer's profit is higher in the case of the decentralized decision-making than that under the centralized decision-making. It occurs because the penalty is not only an incentive but an income for the manufacturer. Furthermore, the required capital decreases as $T$ increases, which indicates that for the supplier with the capital constraint, a long-time contract is better than a short-term contract. Figures 5(c) and 5(d) also indicate that there is little difference between the centralized and decentralized decision-making if the contract period is long or the market price rises.

\subsection{Impact of $T$ and $p$ with capital constraint (under the MS)}

Given that the MS is the best strategy, we analyze the impact of $T$ and $p$ on the decisions and the profits of both firms under this strategy. Let $c_{0}=9$ and the other parameters stay the same value as those first set in Section 7 unless otherwise stated.

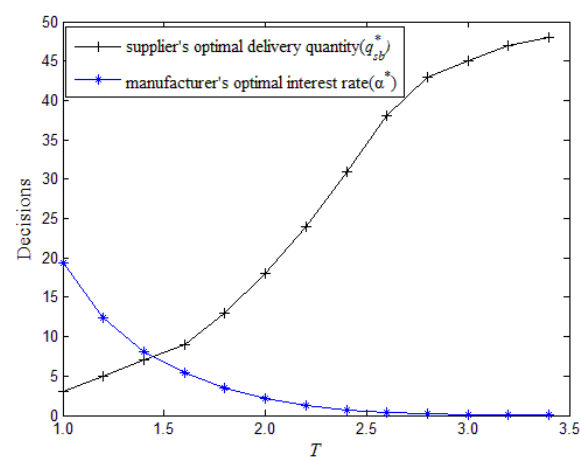

(a) Decisions vs. Contract period

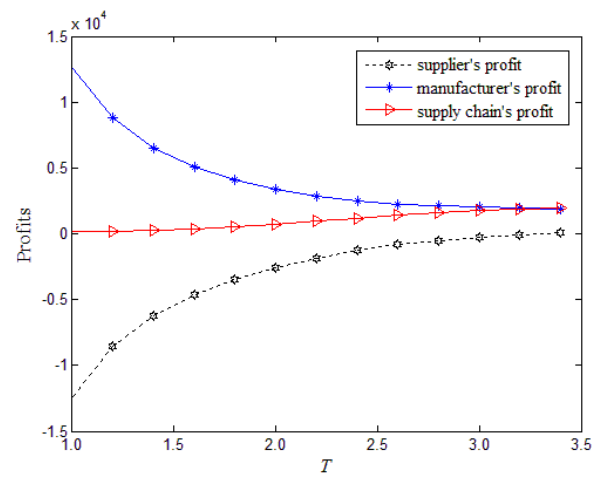

(c) Profits vs. Contract period

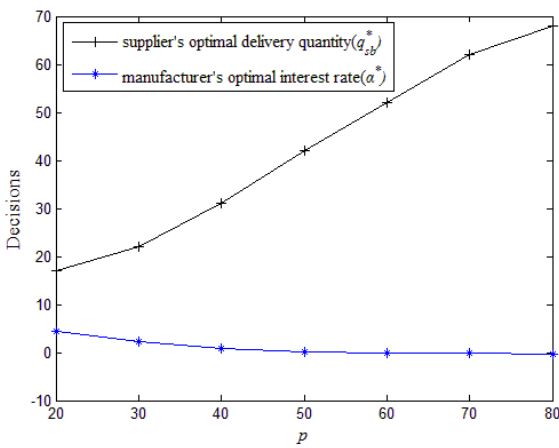

(b) Decisions vs. Market price

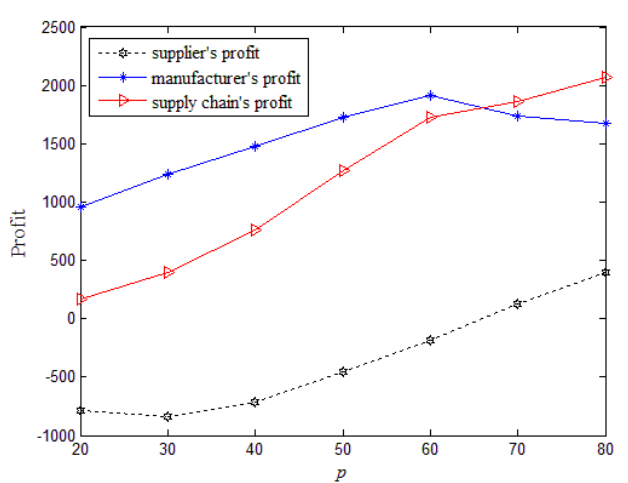

(d) Profits vs. Market price

Figure 6. The impact of $T$ and $p$ on the decisions and profits of both firms under the MS

Figures 6(a) and 6(b) show that the interest rate decreases as $T$ or $p$ increases, while the delivery quantity increases. The situation of the supplier becomes better as the contract period increases, because the supplier can deliver more products to the manufacturer. The manufacturer tries to get more profit from the increase of the price by giving a lower interest rate to increase the delivery quantity. 
Meanwhile, Figure 6(c) implies that the profit of the manufacturer decreases as $T$ increases, while the profit of the supplier increases. However, the profit of the whole supply chain is steady. On the contrary, Figure 6(d) shows that all the profits of the manufacturer, the supplier and the supply chain increase as $p$ increases. We can know that a good situation of the supplier will hurt the profit of the manufacturer. Furthermore, the profits of the manufacturer and the entire supply chain fluctuate significantly. This indicates that the market price fluctuation has great impact on the manufacturer, because the price directly determines the amount of her profit.

\section{Conclusions}

This paper investigates three different strategies for the manufacturer who faces a supply disruption: the ex-ante PS (offering a contract with non-delivery penalty clause to the supplier before the disruption), the ex-post FAS (providing the supplier with financial assistance after the disruption), and the MS (penalty with financial assistance). We find that in most situations MS is the best strategy for the manufacturer, but it is not a win-win strategy because the use of penalty always hurts the supplier's profit. In contrast, the ex-post FAS is the supplier's best strategy. The PS is an ex-ante strategy and has no impact on the delivery quantity when the supplier lacks capital; however, the MS has an impact on the profits of both firms. We also find that, contrary to the conventional wisdom, the optimal delivery quantity for the supply chain under the centralized decision-making is less than that under the decentralized decision-making. However, the disparity between the centralized and decentralized situations becomes less significant as $T$ or $p$ increases. Furthermore, we find that the supplier prefers a long-term contract to a short one because he has more time to deal with the disruption so as to reduce the shortage risk. The financial assistance not only helps the capital-constrained supplier resume his production, but also benefits the manufacturer because of better delivery and the interest income.

Note that the penalties studied in this paper are also known as "liquidated damages." Liquidated damages are those specified in the contract itself. They serve as an incentive not to break the contract. However, they do not have to be directly related to the actual loss caused by breaking the contract. Thus, if the penalties the manufacturer charges are above what the law allows, the manufacturer just chooses a lower penalty.

This study focuses on the strategies of dealing with supply disruption and provides a guideline for 
managers dealing with unexpected supply disruption. For instance, the managers who are in charge of sourcing from the unreliable supplier may, whenever possible, sign a contract which includes penalty terms and offers financial assistance after the occurrence of a supply disruption. Our work also helps managers understand the impact of different supply chain parameters on such a strategy. In practice, however, disruption management may be more complex than any theoretical setting. There are a few ways to extend our study. First, we consider a supply chain with only one supplier and one manufacturer, but in practice, a manufacturer might have multiple suppliers. In this case, if one of these suppliers is subject to a disruption, others can deliver more products to the manufacturer. Nevertheless, the manufacturer might not know the exact number of suppliers that would be disrupted. In other words, the uncertainty of multiple suppliers can be one possible extension of this study. Second, similar to the extant papers on supply disruption, we assume that the order placed with the supplier will be delivered on time if there is no disruption. In practice, however, the supplier may face yield uncertainty due to some factors, such as imperfect production processes, quality problem, material imperfections, and capacity limitations. The second possible extension thus is to explore the disruption problems associated with yield uncertainty (e.g., [45]). Third, the asymmetric information problem is another possible extension of this study. For instance, in our paper, the impact of disruption on the production is the supplier's private information. The supplier may exaggerate the difficulty of the production recovery in order to get more financial assistance.

\section{Acknowledgments}

The authors sincerely thank the editor and the anonymous referees for their constructive and important comments on the paper. Y. Li's research was partially supported by the National Natural Science Foundation of China (NSFC), grant nos. 71372100 and 71572125; X. Qi's research was partially supported by Hong Kong RGC GRF, project number 618311; and G. Cai's research was partially supported by the National Science Foundation (CMMI-1318157) and the National Natural Science Foundation of China (NSFC), grant no. 71228202. 


\section{References}

[1] Treece J. B. Just-too-much single sourcing spurs Toyota purchasing review. Automotive News; March 3, 1997. P. 3

[2] Latour A. Trial by fire: A blaze in Albuquerque sets off major crisis for cell-phone giants. The Wall Street Journal; January 29, 2001

[3] Dawson C, Takahashi Y. Japan's Big 3 Auto Makers to Resume Output. The Wall Street Journal; April 9, 2011.

[4] Bunkley N, Bureau E.T. Japan automakers say operations affected badly. The Economic Times; Mar $21,2011$.

[5] Hendricks K. B, Singhal V. R. Supply chain disruptions and corporate performance. Supply chain disruptions: Theory and practice of managing risks. Gurnani H, Mehrotra A, Ray S, E.d.. New York: Springer; 2012.

[6] Tomlin B, Wang Y. Operational Strategies for Managing Supply Chain Disruption Risk. Handbook of Integrated Risk Management in Global Supply Chains. Kouvelis P, Dong L, Boyabatli O, Li R, Ed. New Jersey: John Wiley \& Sons, 2011.

[7] Tang C. S. Perspectives in supply chain risk management. International Journal of Production Economics 2006; 103(2): 451-488.

[8] Haywood K. GM Helps Axle Maker Avoid Chapter 11. The Wall Street Journal; September 18, 2009.

[9] Taylor R. Ford, GM agrees on \$6.5 million rescue deal for Australian supplier. Reuters; Nov 5, 2012.

[10] Tang S Y, Gurnani H, Gupta D. Managing disruptions in decentralized supply chains with endogenous supply process reliability. Production and Operations Management 2014; 23(7): 1198-1211.

[11] Yu G, Qi X. Disruption management: framework, models, and applications. Singapore: World Scientific Publisher; 2004.

[12] Snyder L. V, Atan Z, Peng P, Rong R, Schmitt A. J, Sinsoysal B. OR/MS Models for Supply Chain Disruptions: A Review, 2012. Working paper, Lehigh University.

[13] Heckmann I, Comes T, Nickel S. A critical review on supply chain risk-Definition, measure and modeling. Omega 2015; 52: 119-132.

[14] Tomlin B. On the value of mitigation and contingency strategies for managing supply chain 
disruption risks. Management Science 2006; 52 (5): 639-657.

[15] Babich V, Burnetas A. N, Ritchken P. H. Competition and diversification effects in supply chains with supplier default risk. Manufacturing \& Service Operations Management 2007; 9(2): 123-146.

[16]Zeng A Z, Xia Y. Building a mutually beneficial partnership to ensure backup supply. Omega 2015; 52: 77-91.

[17] Yang Z, Aydin G, Babich V, Beil D. R. Supply Disruptions, Asymmetric Information, and a Backup Production Option. Management Science 2009; 55 (2): 192-209.

[18] Huang H, Xu H. Dual sourcing and backup production: Coexistence versus exclusivity. Omega 2015;57:22-33.

[19] Schmitt A. J, Snyder L. V. Infinite-horizon models for inventory control under yield uncertainty and disruptions. Computers \& Operations Research 2012; 39(4):850-862.

[20] Sawik T. Selection of supply portfolio under disruption risks. Omega 2011; 39(2): 194-208.

[21] Hu B, Kostamis D. Managing Supply Disruptions when Sourcing from Reliable and Unreliable Suppliers. Production and Operations Management 2014; DOI: 10.1111/poms.12293.

[22] Babich V. Independence of capacity ordering and financial subsidies to risky suppliers. Manufacturing \& Service Operations Management 2010; 12(4): 583-607.

[23] Wadecki A, Babich V, Wu O. Manufacturers' Competition and Subsidies to Suppliers. In: Gurnani H, Mehrotra A, Ray S, editors. Supply Chain Disruptions-Theory and Practice of Managing Risk. London: Springer, 2010.

[24] Hu X, Gurnani H, Wang L. Managing risk of supply disruptions: Incentives for capacity restoration. Production and Operations Management 2012; 22(1):137-150.

[25] Swinney R, Netessine S. Long-term contracts under the threat of supplier default. Manufacturing \& Service Operations Management 2009; 11 (1): 109-127

[26] Iyer A. V, Deshpande V, Wu Z. Contingency management under asymmetric information. Operations Research Letters 2005; 33(6): 572-580.

[27] Gurnani H, Shi M. A. bargaining model for a first-time interaction under asymmetric beliefs of supply reliability, Management Science 2006; 52(6): 865-880.

[28] Shou B, Huang J, Li Z. Managing supply uncertainty under Chain-to-Chain competition, 2009. Working paper, City University of Hong Kong.

[29] Wu D. D, Olson D. L., Dolgui A. Decision making in enterprise risk management: A review and introduction to special issue. Omega 2015; 57:1-4. 
[30] Wu D, Olson D. Enterprise Risk Management: a DEA VaR Approach in Vendor Selection. International Journal of Production Research 2010; 48(16): 4919-4932.

[31] Choi Y, Ye X, Zhao L, Luo A. C. Optimizing enterprise risk management: a literature review and critical analysis of the work of $\mathrm{Wu}$ and Olson. Annals of Operations Research 2015; DOI: 10.1007/s10479-015-1789-5.

[32] Hoyt R. E, Liebenberg A. P. The value of enterprise risk management. Journal of Risk and Insurance 2011; 78(4): 795-822.

[33] Wu D. D, Chen S. H, \& Olson D. L. Business intelligence in risk management: Some recent progresses. Information Sciences 2014; 256: 1-7.

[34] Beasley M. S, Clune R, Hermanson D. R. Enterprise risk management: An empirical analysis of factors associated with the extent of implementation. Journal of Accounting and Public Policy 2005; 24(6): 521-531.

[35] Wu D, Wu D. D, Zhang Y, \& Olson D. L. Supply chain outsourcing risk using an integrated stochastic-fuzzy optimization approach. Information Sciences 2013; 235: 242-258.

[36] Li Y, Zhen X, Cai X. Trade credit insurance, capital constraint, and the behavior of manufacturers and banks. Annals of Operations Research 2014; DOI:10.1007/s10479-014-1602-x.

[37] Arena M, Arnaboldi M, Azzone G. The organizational dynamics of enterprise risk management. Accounting, Organizations and Society 2010; 35(7): 659-675.

[38] Cachon G. P, Netessine S. Game theory in supply chain analysis. Handbook of Quantitative Supply Chain Analysis. Springer US, 2004: 13-65.

[39] Qi X, Bard J. F, Yu G. Supply chain coordination with demand disruptions. Omega 2004; 32(4): 301-312.

[40] Cachon G. P. The allocation of inventory risk in a supply chain: push, pull, and advance-purchase discount contracts. Management Science 2004; 50(2): 222-238.

[41] Cachon G. P. Supply chain coordination with contracts. In: Graves S, de Kok T, editors. Handbooks in operations research and management science: supply chain management. Amsterdam: North-Holland, 2003.

[42] Tomlin B. Capacity investments in supply chains: Sharing the gain rather than sharing the pain. Manufacturing \& Service Operations Management 2003; 5(4): 317-333.

[43] Jing B, Chen X, Cai, G. Equilibrium Financing in a Distribution Channel with Capital Constraint. Production and Operations Management 2012; 21(6): 1090-1101. 
[44] Cai G, Chen X and Xiao Z. The Roles of Bank and Trade Credits: Theoretical Analysis and Empirical Evidence. Productions and Operations Management 2014; 23(4): 583-598.

[45] Schmitt A. J, Snyder L. V. Infinite-horizon models for inventory control under yield uncertainty and disruptions. Computers \& Operations Research 2012; 39(4):850-862.

\section{Appendix}

Proof of Theorem 1. Differentiating Eq. (1) with respect to $q$ yields

$$
\frac{\partial \pi_{s e}(q)}{\partial q}=w\left(q^{0}\right)-\frac{4 q}{k T^{2}}+e
$$

Furthermore, we have

$$
\frac{\partial^{2} \pi_{s e}(q)}{\partial q^{2}}=-\frac{4}{k T^{2}} .
$$

Since $\frac{\partial^{2} \pi_{s e}(q)}{\partial q^{2}}<0, \pi_{s e}(q)$ is strictly concave in $q$ and the optimal delivery quantity is unique. Let $q_{s e}$ satisfy $\frac{\partial \pi_{s e}(q)}{\partial q}=0$, we get $q_{s e}=\frac{e+w\left(q^{0}\right)}{4} k T^{2}$. Taking the capital constraint consideration, if $R \geq c_{e} q_{s e}=\frac{k T^{2}\left(w\left(q^{0}\right)+e\right)^{2}}{8}$, then the supplier will have enough initial capital for operation, and the optimal delivery quantity is $q_{s e}^{*}=\frac{e+w\left(q^{0}\right)}{4} k T^{2}$; otherwise, if $R<c_{e} q_{s e}=\frac{k T^{2}\left(w\left(q^{0}\right)+e\right)^{2}}{8}$, since the supplier's profit function $\pi_{s e}(q)$ is increasing for $q \in\left[0, q_{s e}^{*}\right]$, the supplier will use all the cash to produce and $q_{s e}^{*}=T \sqrt{\frac{R k}{2}}$. Notice that the delivery quantity must be less than or equal to $q^{0}$, so the optimal delivery quantity is $q^{0}$ if $q_{s e}^{*} \geq q^{0}$; otherwise, the optimal delivery quantity is $q_{s e}^{*}$, if $q_{s e}^{*}<q^{0}$.

Proof of Lemma 1. In the worst case, i.e., $R<\frac{k T^{2}\left(w\left(q^{0}\right)+e\right)^{2}}{8}$, all the cash of the supplier 
is used for the production. Especially, if the cash flow is negative at time $T$, i.e., $\left(w\left(q^{0}\right)+e\right) \sqrt{\frac{R k T^{2}}{2}}-e q^{0}<0$, then in this case $R<\frac{2}{k T^{2}}\left[\frac{e}{w\left(q^{0}\right)+e} q^{0}\right]^{2}$ and the suppler cannot pay for the penalty and goes bankrupt. Therefore, let $G=\frac{2}{k T^{2}}\left[\frac{e}{w\left(q^{0}\right)+e} q^{0}\right]^{2}$, we obtain $\frac{\partial G}{\partial e}=\frac{4}{k T^{2}} \frac{w\left(q^{0}\right)\left(q^{0}\right)^{2} e}{\left(w\left(q^{0}\right)+e\right)^{3}}>0$. It indicates that as $e$ increases, more the initial capital is needed to ensure no bankruptcy in the case of disruption. Thus, $G$ is a decreasing function of $T$.

Proof of Theorem 3. In the case of LP, $q_{s e}^{*}=\frac{e+w\left(q^{0}\right)}{4} k T^{2}$. Differentiating Eq. (3) with respective to $e$ yields

$$
\frac{\partial \pi_{r e}(e)}{\partial e}=\rho\left\{\left[(p-v) \bar{F}\left(q_{s e}^{*}\right)-\left(w\left(q^{0}\right)+e+c_{r}-v\right)\right] \frac{\partial q_{s e}^{*}}{\partial e}+q^{0}-q_{s e}^{*}\right\} .
$$

Since $q_{s e}^{*}=\frac{e+w\left(q^{0}\right)}{4} k T^{2}$, we have $\frac{d q_{s e}^{*}}{d e}=\frac{k T^{2}}{4}$ and $\frac{\partial^{2} q_{s e}^{*}}{\partial e^{2}}=0$.

Taking the second order derivatives with respective to $e$, we obtain

$$
\begin{aligned}
\frac{\partial^{2} \pi_{r e}(e)}{\partial e^{2}} & =\rho\left\{\left[-2-(p-v) f\left(q_{s e}^{*}\right) \frac{\partial q_{s e}^{*}}{\partial e}\right] \frac{\partial q_{s e}^{*}}{\partial e}+\left[(p-v) \bar{F}\left(q_{s e}^{*}\right)-\left(w\left(q^{0}\right)+e+c_{r}-v\right] \frac{\partial^{2} q_{s e}^{*}}{\partial e^{2}}\right\} .\right. \\
& =\rho\left[-2-(p-v) f\left(q_{s e}^{*}\right) \frac{k T^{2}}{4}\right] \frac{k T^{2}}{4}
\end{aligned}
$$

For $f\left(q_{s e}^{*}\right)>0$, we get $\frac{\partial^{2} \pi_{r e}(e)}{\partial e^{2}}<0$. So, the profit of the manufacturer is a strictly concave function in $e$ and the optimal unit penalty exists and is unique. Let $e^{*}$ satisfy

$$
\begin{aligned}
& \frac{\partial \pi_{r e}(e)}{\partial e}=0 \text {, then } \\
& \qquad(p-v) \bar{F}\left(q_{s e}^{*}\right)-\left(w\left(q^{0}\right)+e^{*}+c_{r}-v\right)=4 /\left(k T^{2}\right)\left(q_{s e}^{*}-q^{0}\right) .
\end{aligned}
$$

After simplifying the above equation, we have

$$
e^{*}=\frac{(p-v) \bar{F}\left(q_{s e}^{*}\left(e^{*}\right)\right)+4 q^{0} / k T^{2}-\left(c_{r}-v\right)}{2}-w\left(q^{0}\right), \text { which is the global optimum. }
$$

Considering the constraint condition, the optimal unit penalty 


$$
e^{*}=\min \left\{\frac{(p-v) \bar{F}\left(q_{s e}^{*}\left(e^{*}\right)\right)+4 q^{0} / k T^{2}+\left(v-c_{r}\right)}{2}-w\left(q^{0}\right), \sqrt{\frac{8 R}{k T^{2}}}-w\left(q^{0}\right)\right\} .
$$

Proof of Lemma 2. In the case of LP, differentiating $(p-v) \bar{F}\left(q_{s e}^{*}\right)-\left(w\left(q^{0}\right)+e^{*}+c_{r}-v\right)=4 /\left(k T^{2}\right)\left(q_{s e}^{*}-q^{0}\right)$ with respect to $T$, we have

$$
-\left[(p-v) f\left(q_{s e}^{*}\right) k T^{2} / 4+2\right] \frac{\partial e^{*}}{\partial T}=\frac{8\left(q^{0}-q_{s e}^{*}\right)}{k T^{3}}+\left(w\left(q^{0}\right)+e^{*}\right)\left[\frac{4+(p-v) f\left(q_{s e}^{*}\right) k T^{2}}{2 T}\right],
$$

since $q^{0} \geq q_{s e}^{*}, \frac{\partial e^{*}}{\partial T}<0$, i.e., $e^{*}$ is a decreasing function in $T$. If $e^{*}=\sqrt{\frac{8 R}{k T^{2}}}-w\left(q^{0}\right)$, it is easy to find that $e^{*}$ is a decreasing function in $T$. In the case of HP, differentiating $\frac{T w\left(q^{0}\right) \sqrt{R k}}{\sqrt{2} q^{0}-T \sqrt{R k}}$ with respect to $T$, we obtain $\frac{q^{0} w\left(q^{0}\right) \sqrt{2 R k}}{\left(\sqrt{2} q^{0}-T \sqrt{R k}\right)^{2}}>0$, that is, $e^{*}$ is a increasing function in $T$.

Proof of Lemma 3. When $e \leq \sqrt{\frac{8 R}{k T^{2}}}-w\left(q^{0}\right) \quad$ differentiating $(p-v) \bar{F}\left(q_{s e}^{*}\right)-\left(w\left(q^{0}\right)+e^{*}+c_{r}-v\right)=4 /\left(k T^{2}\right)\left(q_{s e}^{*}-q^{0}\right)$ with respect to $q^{0}$, we have $\frac{\partial e^{*}}{\partial q^{0}}=-\frac{\partial w}{\partial q^{0}}+\frac{16}{k T^{2}}\left[\frac{1}{8+k T^{2}(p-v) f(q)}\right]$. Since $\frac{\partial w}{\partial q^{0}} \leq 0, \frac{\partial e^{*}}{\partial q^{0}}>0$, i.e., $e^{*}$ is an increasing function in $q^{0}$. When $e>\sqrt{\frac{8 R}{k T^{2}}}-w\left(q^{0}\right)$, differentiating $\frac{T w\left(q^{0}\right) \sqrt{R k}}{\sqrt{2} q^{0}-T \sqrt{R k}}$ with respect to $q^{0}$, since $\frac{\partial w}{\partial q^{0}} \leq 0$, we obtain $\frac{T \sqrt{2 R k}\left[\left(q^{0}-\frac{T \sqrt{R k}}{2}\right) \frac{\partial w}{\partial q^{0}}-w\left(q^{0}\right)\right]}{\left(\sqrt{2} q^{0}-T \sqrt{R k}\right)^{2}}<0$, i.e., $e^{*}$ is a decreasing function in $q^{0}$.

Proof of Theorem 4. Substituting $c_{e}=\frac{2 q}{k T^{2}}$ into Eq. (4), taking partial derivatives with respective to $q$, we obtain

$$
\frac{\partial \pi_{c e}(q)}{\partial q}=(p-v) \bar{F}(q)-\left(c_{r}-v\right)-\frac{4}{k T^{2}} q .
$$

Furthermore, we have 


$$
\frac{\partial^{2} \pi_{c e}(q)}{\partial q^{2}}=-(p-v) f(q)-\frac{4}{k T^{2}}
$$

Since $f(q)>0$ and $p-v>0$, we have $\frac{\partial^{2} \pi_{c e}(q)}{\partial q^{2}}<0$. That is, the supply chain profit is a strict concave function in $q$. Let $\hat{q}_{c e}$ be the optimal delivery quantity by solving $\frac{\partial \pi_{c e}(q)}{\partial q}=0$. It is clear that $\hat{q}_{c e}$ satisfies $(p-v) \bar{F}\left(\hat{q}_{c e}\right)=\frac{4}{k T^{2}} \hat{q}_{c e}+c_{r}-v$. Taking the capital constraint into consideration, when $R \geq \frac{2 \hat{q}_{c e}{ }^{2}}{k T^{2}}$, the supplier with enough cash is not capital-constrained, and produces and delivers $\hat{q}_{c e}$ units products.

Because the supply chain profit function is increasing in $q$ for $q \in\left[0, \hat{q}_{c e}\right]$, when $R<\frac{2 \hat{q}_{c e}{ }^{2}}{k T^{2}}$ the supplier uses up the initial cash to increase the production quantity, and then maximizes the supply chain profit. Therefore, in this case, the optimal delivery quantity is $T \sqrt{\frac{R k}{2}}$

Proof of Lemma 4. When $R \geq \frac{2 \hat{q}_{c e}{ }^{2}}{k T^{2}}, \quad q_{c e}^{*}=\hat{q}_{c e} \quad$ and $\quad$ we have $(p-v) \bar{F}\left(q_{c e}^{*}\right)=\frac{4}{k T^{2}} q_{c e}^{*}+c_{r}-v \quad$. Since $\quad c_{c e}^{*}=\frac{2 q_{c e}^{*}}{k T^{2}} \quad$ and $\quad c_{s}<2 c_{c e}^{*} \quad, \quad$ we have $F\left(q_{c e}^{*}\right)=\frac{p-\left(c_{r}+2 c_{c e}^{*}\right)}{p-v}<\frac{p-c}{p-v}=F\left(q^{0}\right)$, i.e., $F\left(q_{c e}^{*}\right)<F\left(q^{0}\right)$. Here, $F(\cdot)$ is strictly increasing; thus, $q_{c e}^{*}<q^{0}$.

Proof of Theorem 5. From Theorem 1, when $R \geq \frac{k T^{2}\left(w\left(q^{0}\right)+e\right)^{2}}{8} \quad$ and $\frac{e+w\left(q^{0}\right)}{4} k T^{2} \leq q^{0}$, we know $q_{s e}^{*}=\frac{e+w\left(q^{0}\right)}{4} k T^{2}$, which is an increasing function in $e$. 
Thus, there exists a unique $e$ such that $q_{s e}^{*}=q_{c e}^{*}$. Substituting $q_{s e}^{*}=\frac{e+w\left(q^{0}\right)}{4} k T^{2}$ into $q_{s e}^{*}=q_{c e}^{*}$, we obtain $e=\frac{4}{k T^{2}} q_{c e}^{*}-w\left(q^{0}\right)$. Let $e^{0}=\frac{4}{k T^{2}} q_{c e}^{*}-w\left(q^{0}\right)$, the theorem is proven.

Proof of Theorem 6. Differentiating Eq. (5) with respective to $q$, we obtain

$$
\frac{d \pi_{s b}(q)}{d q}=w\left(q^{0}\right)-\frac{4 q}{k T^{2}}+e-\frac{4 q \alpha}{k T^{2}}+c_{0} \alpha
$$

The second order derivative with respect to $q$ is given by

$$
\frac{d^{2} \pi_{s b}(q)}{d q^{2}}=-\frac{4}{k T^{2}}(1+\alpha) .
$$

We can know $\frac{d^{2} \pi_{s b}(q)}{d q^{2}}<0$, so the supplier's profit function is a strictly concave function in $q$. Let $\hat{q}_{s b}$ be the optimal delivery quantity by solving $\frac{d \pi_{s b}(q)}{d q}=0$. Thus, we have

$$
\hat{q}_{s b}=\frac{w\left(q^{0}\right)+e+c_{0} \alpha}{4(1+\alpha)} k T^{2}
$$

Since $B^{*}=c_{1} \hat{q}_{s b}$, we get $B^{*}=\frac{\left(w\left(q^{0}\right)+e+c_{0} \alpha\right)\left(w\left(q^{0}\right)+e-c_{0} \alpha-2 c_{0}\right)}{8(1+\alpha)^{2}} k T^{2}$.

When $q=0, \pi_{s e}(0)=\pi_{s b}(0)=-e q^{0}<0 . \pi_{s e}(q)-\pi_{s b}(q)=\left(c_{e}-c_{0}\right) q>0$, and

$$
\begin{aligned}
\left.\frac{d \pi_{s b}(q)}{d q}\right|_{q=q_{s e}^{*}} & =w\left(q^{0}\right)-\frac{4 q_{s e}^{*}}{k T^{2}}+e-\frac{4 q_{s e}^{*} \alpha}{k T^{2}}+c_{0} \alpha \\
& =-\frac{4 q_{s e}^{*}}{k T^{2}}+\left(w\left(q^{0}\right)+e\right)-\frac{4 q_{s e}^{*} \alpha}{k T^{2}}+c_{0} \alpha \\
& =\left.\frac{d \pi_{s e}(q)}{d q}\right|_{q=q_{s e}^{*}}-\frac{4 q_{s e}^{*} \alpha}{k T^{2}}+c_{0} \alpha=\left(c_{0}-\frac{4 q_{s e}^{*}}{k T^{2}}\right) \quad \alpha<0
\end{aligned}
$$

Let $q_{L}$ be the minimum that satisfies $\pi_{s b}\left(\hat{q}_{s b}\right)=\pi_{s e}\left(q_{L}\right)$. We obtain the results shown in Figure 7. 


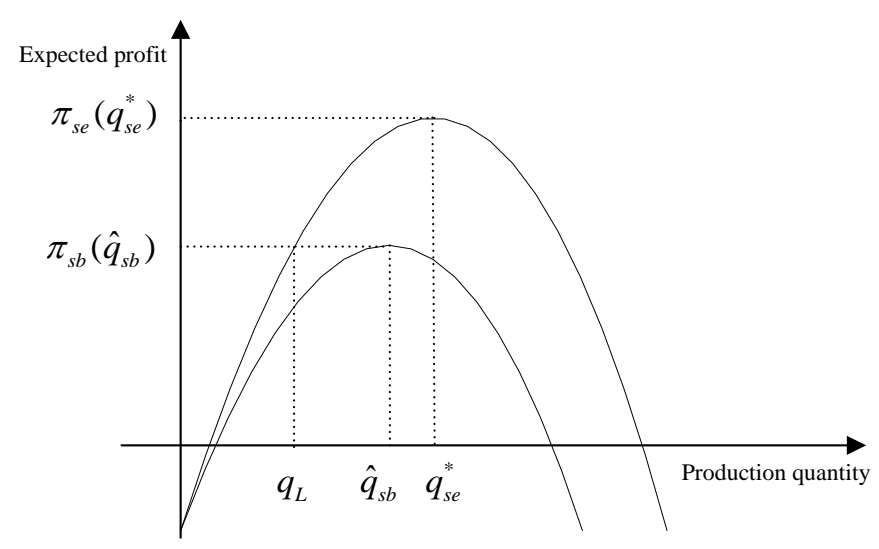

Figure 7. The expected profits before and after the financial assistance

If the supplier seeks to maximize his own profit, from Figure 7 we know that when $R \geq c_{e} q_{L}=\frac{2 q_{L}^{2}}{k T^{2}}\left(\frac{R}{c_{e}} \geq q_{L}\right)$, the supplier obtains more profits by using his own capital than by accepting the financial assistance, so he does not accept financial assistance. That is, $B=0$ and the optimal delivery quantity $q_{s b}^{*}=T \sqrt{\frac{R k}{2}}$. When $R \leq \frac{2 q_{L}^{2}}{k T^{2}}$, the supplier can improve his profit by the financial assistance. So he accepts it and produces $q_{s b}^{*}=\hat{q}_{s b}=\frac{w\left(q^{0}\right)+e+c_{0} \alpha}{4(1+\alpha)} k T^{2}$ units. On the other hand, if the supplier seeks to meet the contract requirements rather than to maximize the profit, the financial assistance can help him increase the delivery quantity to some extent.

Proof of Lemma 5. Differentiating $q_{s b}^{*}$ with respective to $\alpha$, we have $\frac{\partial q_{s b}^{*}}{\partial \alpha}=\frac{c_{0}-w\left(q^{0}\right)-e}{4(1+\alpha)^{2}} k T^{2}$. Given that $c_{0}<w\left(q^{0}\right)+e, \frac{\partial q_{s b}^{*}}{\partial \alpha}<0$. Thus, $q_{s b}^{*}$ decreases as $\alpha$ increases. Differentiating $B^{*}$ with respect to $\alpha$ and $c_{0}$, we obtain $\frac{\partial B^{*}}{\partial \alpha}=\left(\frac{4 q_{s b}^{*}}{k T^{2}}-c_{0}\right) \frac{\partial q_{s b}^{*}}{\partial \alpha}<0$ and $\frac{\partial B^{*}}{\partial c_{0}}=-\frac{\left(w\left(q^{0}\right)+e\right)+c_{0} \alpha(2+\alpha)}{4(1+\alpha)^{2}} k T^{2}<0$. This means that $B^{*}$ decreases as $\alpha$ or $c_{0}$ increases.

Proof of Theorem 7. Differentiating Eq.(6) with respective to $\alpha$ yields 
$\frac{\partial \pi_{r b}(\alpha)}{\partial \alpha}=\left\{(p-v) \bar{F}\left(q_{s b}^{*}\right)-\left[\left(w\left(q^{0}\right)+c_{r}-v+e\right]+\left(\frac{4 q_{s b}^{*}}{k T^{2}}-c_{0}\right) \alpha\right\} \frac{\partial q_{s b}^{*}}{\partial \alpha}+\left(\frac{2 q_{s b}^{*}}{k T^{2}}-c_{0}\right) q_{s b}^{*}\right.$

Since $q_{s b}^{*}=\frac{w\left(q^{0}\right)+e+c_{0} \alpha}{4(1+\alpha)} k T^{2}$

$\frac{\partial q_{s b}^{*}}{\partial \alpha}=\frac{c_{0}-w\left(q^{0}\right)-e}{4(1+\alpha)^{2}} k T^{2}$ and $\frac{\partial^{2} q_{s b}^{*}}{\partial \alpha^{2}}=\frac{w\left(q^{0}\right)+e-c_{0}}{2(1+\alpha)^{3}} k T^{2}$

Let $\alpha^{*}$ satisfy $\frac{d \pi_{r b}(\alpha)}{d \alpha}=0$, and

$$
\begin{aligned}
\left.\frac{16(1+\alpha)^{4}}{k T^{2}} \frac{\partial^{2} \pi_{r b}(\alpha)}{\partial \alpha^{2}}\right|_{\alpha=\alpha^{*}}=-f\left(q_{s b}{ }^{*}\right) k T^{2}(p-v)\left(e+w-c_{0}\right)^{2} \\
-4(2+\alpha)\left(e+w-c_{0}\right)^{2}+4(1+\alpha)\left(e+w+\alpha c_{0}\right)\left[e+w-(\alpha+2) c_{0}\right]
\end{aligned}
$$$$
H=-\left(w\left(q^{0}\right)+e-c_{0}\right)^{2}(2+\alpha)+\left(w\left(q^{0}\right)+e-2 c_{0}-c_{0} \alpha\right)\left(w\left(q^{0}\right)+e+c_{0} \alpha\right)(1+\alpha), \text { then }
$$

$$
\begin{aligned}
& H=\left(w\left(q^{0}\right)+e-2 c_{0}-c_{0} \alpha\right)\left(w\left(q^{0}\right)+e+c_{0} \alpha\right)(1+\alpha)-\left(w\left(q^{0}\right)+e-c_{0}\right)^{2}(2+\alpha) \\
& <\left(w\left(q^{0}\right)+e-2 c_{0}-c_{0} \alpha\right)\left(w\left(q^{0}\right)+e+c_{0} \alpha\right)-\left(w\left(q^{0}\right)+e-c_{0}\right)^{2} \\
& =-(1+\alpha)^{2} c_{0}^{2}<0
\end{aligned}
$$

So $\left.\frac{\partial^{2} \pi_{r b}(\alpha)}{\partial \alpha^{2}}\right|_{\alpha=\alpha^{*}}<0$. That is, the optimal interest rate $\alpha^{*}$ can be obtained from $\frac{d \pi_{r b}(\alpha)}{d \alpha}=0$, thus it satisfies

$$
\begin{aligned}
& \frac{2 \alpha^{*}\left(w\left(q^{0}\right)+e-c_{0}\right)^{2}}{1+\alpha^{*}}-\left(w\left(q^{0}\right)+e+\alpha^{*} c_{0}\right)\left(w\left(q^{0}\right)+e-c_{0}\left(2+\alpha^{*}\right)\right) \\
& =2\left(w\left(q^{0}\right)+e-c_{0}\right)\left[w\left(q^{0}\right)+e+c_{r}-v-(p-v) \bar{F}\left(q_{s b}^{*}\right)\right]
\end{aligned}
$$

Let $w\left(q^{0}\right)+e-c_{0}=M$, we have

$$
\frac{3+\alpha^{*}}{1+\alpha^{*}} M^{2}=2 M\left[(p-v) \bar{F}\left(q_{s b}^{*}\right)+v-\left(c_{r}+c_{0}\right)\right]+c_{0}^{2}\left(1+\alpha^{*}\right)^{2} .
$$

Proof of Lemma 6. Because the contract has been signed before the disruption happens, the purchase price $w\left(q^{0}\right)$ and $e$ are fixed. $\alpha^{*}$ can be regarded as a function in $p$. Taking derivative of $\frac{3+\alpha^{*}}{1+\alpha^{*}} M^{2}=2 M\left[(p-v) \bar{F}\left(q_{s b}^{*}\right)+v-\left(c_{r}+c_{0}\right)\right]+c_{0}{ }^{2}\left(1+\alpha^{*}\right)^{2}$ with respect 
to $p$, we obtain

$$
\left(2 c_{0}^{2}\left(1+\alpha^{*}\right)+\frac{4+(p-v) f\left(q_{s b}^{*}\right) k T^{2}}{2\left(1+\alpha^{*}\right)^{2}} M^{2}\right) \frac{d \alpha^{*}}{d p}=-2 M \bar{F}\left(q_{s b}^{*}\right) .
$$

Since $M>0, f\left(q_{s b}^{*}\right)>0$ and $p-v>0, \frac{d \alpha^{*}}{d p}<0$. Lemma 6 has been proven. 